\title{
Arreglos nupciales, iras santas y disputas regionales: apuntes para la microhistoria de Chiapas, 1911-1912
}

Diana Guillén

INSTITUTO MORA

\begin{abstract}
El artículo analiza los vínculos entre un acto de dimensiones privadas (el matrimonio religioso del gobernador maderista en Chiapas), con procesos sociales derivados de las historias local y nacional. La anécdota que condujo a la desaparición temporal de la Iglesia católica en Tuxtla, es rescatada como parte de escenarios en los que, independientemente de lo que sucedía en otros puntos del país, las permanencias eran mayores que las mudanzas y la disputa principal giraba alrededor de una centralidad político-espacial interna.
\end{abstract}

$\mathbf{L}$ as reflexiones sobre la revolución mexicana se han enriquecido al incorporar matices regionales que dan vida a procesos, actores y escenarios no siempre rescatados por la historiografia oficial. Las principales ideas surgidas de esta última a propósito del plano político, pusieron durante largo tiempo especial atención en la derrota de las elites que representaban al régimen porfirista, pero las condiciones internas que acompañaron el ocaso de tales grupos, o bien que permitieron su reinserción en el nuevo sistema, tendieron a tratarse de manera tangencial e incluso a perderse en el camino.
Los esfuerzos por rescatar trayectorias particulares resultan pues útiles para avanzar en el conocimiento de la globalidad en la que abrevan. A partir de diversos objetos de estudio existen ya propuestas sistemáticas en este sentido, ${ }^{1}$ y nuestra idea es sumarnos a ellas recuperando un acontecimiento en el que se mezclan los ámbitos público y

\footnotetext{
${ }^{1}$ Estamos pensando tanto en los textos de carácter monográfico promovidos a partir de la década de los sesenta por el Instituto de Estudios Históricos de la Revolución Mexicana para cada una de las entidades federativas, como en las investigaciones con ejes temáticos específicos elaboradas sobre todo a partir de los ochenta.
} 
privado y en el que, más allá del carácter anecdótico que lo envuelve, se pueden rastrear líneas importantes de la historia chiapaneca.

En este sentido rescatamos los detalles de un acto de dimensiones microsociales (el matrimonio religioso del gobernador maderista en Chiapas) e intentamos vincularlo con tendencias de mayor alcance que parecen decantar en él. Según veremos a lo largo del trabajo, alrededor de la boda, que por presiones sociopolíticas debió realizarse en un sitio distinto al previsto, y de la reacción que esto provocó en el obispo de la entidad, aparece de inmediato un complejo entramado de tipo piramidal, en cuyo punto más alto se ubicaban ciertos grupos de poder enfrascados en conflictos lejanos a la guerra que se desataba en el centro y el norte del país y en cuya base tomaban forma conglomerados indígenas que metamorfoseaban su ancestral marginación en contrapesos capaces de inclinar, a través del enfrentamiento abierto, la balanza de las fuerzas locales.

Para estructurar la exposición empezamos por describir los ambientes estructural y coyuntural que rodearon el enlace; posteriormente nos referimos a los principales protagonistas de la trama que este último generó y, para concluir, establecemos las pistas sobre la historia de la entidad a las que conduce el episodio familiar.

\section{LUCES Y SOMBRAS REGIONALES}

A fines de 1911 Francisco I. Madero ocupaba la presidencia de México y ponía fin a la larga dictadura que per- mitió consolidar un Estado nacional preñado de contradicciones de todo tipo. La capacidad de Porfirio Díaz para controlar y a la vez utilizar las estructuras de poder locales que desde la colonia se habían ido construyendo, fue quizá la piedra angular de los cambios que entre 1877 y 1911 transformaron la fisonomía del país. ${ }^{2}$ Durante ese lapso se buscó denodadamente una modernidad cuyos cimientos requerían de estructuras distintas a las que se poseían; el endeble resultado terminaría por mostrar sus límites cuando el descontento de amplias capas de la sociedad se transformó en cuestionamientos capaces de aglutinar intereses diversos en contra del régimen imperante.

La revolución iniciada en 1910 condensaba requerimientos de distinto tipo (desde demandas populares encaminadas a revertir procesos de despojo e inequidad, hasta banderas de libera. ción económica y política encabezadas por ciertos sectores empresariales y clases medias citadinas), sin embargo, en el fondo representaba la necesidad de ajustar las bases de una sociedad en la que predominaban relaciones de corte oligárquico, con los avances vividos en ciertos rubros durante las tres décadas anteriores. ${ }^{3}$

Los niveles de desajuste entre uno y otro plano variaban dependiendo de la zona e incluso de la entidad de la que se tratara. Ello explica en parte las

\footnotetext{
${ }^{2}$ Las caracteristicas de las redes sociopolíticas tejidas durante el porfiriato pueden consultarse en Guerra, México, 1988.

${ }^{3}$ Una buena síntesis de las transformaciones impulsadas por Díaz puede encontrarse en Rosenzweig, "Desarrollo", 1988.
} 
diferencias regionales con respecto a las diversas fases de la gesta (la armada inclusive) y contribuye a entender las permanencias que, en el caso de Chiapas, disminuyeron los alcances transformadores de un ambiente revolucionario. A estas alturas podemos afirmar que las relaciones establecidas en el estado durante el porfiriato lograron subsistir y se volvieron funcionales para el régimen que se inauguraba.

En los albores del siglo $\mathrm{XX}$, Chiapas seguía aislada del centro del país. Formalmente se había integrado a México en $1824,{ }^{4}$ pero las dificultades en el terreno de las comunicaciones y el escaso interés con el que desde un principio se le trató, favorecieron el mantenimiento de vínculos (sobre todo económicos y sociales) con Guatemala. Aunque la labor emprendida por Emilio Rabasa (1891-1894) y sus sucesores (1894-1911) contribuyó a mejorar la situación de atraso y confinamiento a la que había conducido el posicionamiento secundario de la frontera sur dentro del territorio nacional, sus rasgos esenciales se mantuvieron.

En el plano material, bajo la égida rabasista se buscó resolver algunos de

\footnotetext{
4 El 24 de septiembre de ese año se declaró solemnemente el ingreso a la federación. En el acta respectiva se menciona la presencia de miembros destacados de corporaciones importantes en el plano local (Cabildo sede vacante, Obispado, Jefatura Política y Ayuntamiento, Intendencia con los empleados de Hacienda, prelados y vecindario de distinción) y de un agente del Supremo Gobierno de la nación mexicana. Este último ofreció toda su protección para encaminar al estado de Chiapas "a su mayor rango y felicidad". El texto completo de la Declaración puede consultarse en Espinoza, Independencia, 1918, pp. 65-68.
}

los principales problemas que aquejaban al estado, pero a la par de las metas alcanzadas entre 1894 y 1911 , se agudizaron las precarias condiciones de vida para la mayoría de sus habitantes. ${ }^{5}$ Podríamos afirmar que la contradicción entre los impulsos modernizantes del porfiriato y sus entrañas atávicas se magnificó en un escenario impregnado de racismos y donde los contrastes culturales se aprovecharon a la hora de reproducir la servidumbre indígena y de consolidar la estructura agraria derivada de ella.

Baste recordar que si bien a fines del siglo XIX la necesidad de superar añejos resabios se había integrado al discurso compartido por políticos y hacendados chiapanecos, cuando en 1896 el gobernador Francisco León impulsó un Congreso Agrícola para reglamentar el uso de mano de obra cautiva aparecieron de inmediato las dificultades de romper vínculos y engranajes centrales para el funcionamiento social. ${ }^{6}$ Los términos en los que se negó cualquier posibilidad de cambio, después de largas deliberaciones y críticas al sistema imperante, ilustran las disyuntivas finiseculares de la elite chiapaneca:

Nos faltan todos los elementos que produce la civilización; no tenemos caminos de herradura, carecemos de carretera, estamos muy lejos de los ferrocarriles, la mecánica está incipiente

\footnotetext{
${ }^{5}$ En otro trabajo hemos tratado con más detalle las características del rabasismo. Véase Pérez y Guillén, Chiapas, 1994, pp. 156-199.

${ }^{6}$ Para un buen análisis de las implicaciones estructurales de romper con el trabajo servil, véase García de León, Resistencia, 1985, vol. II, pp. 165-166.
} 
todavía; sin más causa que la dificultad del transporte, el comercio de nuestros productos está circunscrito casi casi a nuestro propio consumo, como si nos hubiéramos formado el propósito de ser egoístas; el comercio de exportación reducido a unas cuantas manos; el crédito carcomido por el agiotista; la industria y las artes en un estado de atraso latente, y, sin embargo, hablamos de progreso e intentamos dar pasos de gigante cuando en realidad no somos por hoy más que pigmeos [...] se necesita que el tiempo, según que caminamos más o menos despacio, venga modificando las circunstancias económicas en medio de las que vivimos para que sin necesidad de expedir leyes, atacar a la agricultura, disminuir las rentas del erario, herir el capital del agricultor, deprimir las libertades del sirviente y sin esfuerzo alguno que se encamine a conculcar la gran ley de la tierra, lleguemos al punto final de nuestros deseos. En consecuencia, opinamos que nos es llegada la época de suprimir el sistema de mozos adeudados en el estado. ${ }^{7}$

Aunque por razones de espacio se cite sólo un fragmento, el conjunto del texto ofrece pistas que llevan a comprobar el nivel de obsolescencia del agro chiapaneco. Las carencias estructurales a las que alude el documento eran reales: las vías de comunicación han constituido desde siempre un talón de Aquiles ${ }^{8}$ que se ha aprovechado para obtener ventajas diferenciales en el comercio. A punto de concluir el

${ }^{7}$ Documentos, 1896 , pp. $48-49$ (se modificaron algunos elementos de la puntuación y de la ortografia originales para facilitar la lectura).

${ }^{8}$ El desarrollo de las mismas para la época que nos ocupa, puede consultarse en Castañón, "Panorama", 1951. siglo, los llamados coyotes siguen controlando las redes internas de esta actividad, de allí que un territorio menos articulado (como el que predominaba al iniciar el siglo $\mathrm{XX}$ ) agudizara las dificultades para intercambiar cualquier producto. Por lo que se refiere a las exportaciones, el café era quizá la mercancía más importante de la época, y su colocación en el exterior pasaba casi siempre por los finqueros alemanes del Soconusco.

Los créditos constituían por lo general el resultado de transacciones privadas, situación que se reflejaba en condiciones poco equitativas y alejadas de una mentalidad empresarial que buscara incrementar la productividad. En medio de tal escenario, la servidumbre por deudas resultaba un eslabón importante de las cadenas que sujetaban a la ruralidad chiapaneca.

Además de las razones económicas y sociales en las que se refugiaban quienes se oponían a modernizar el agro, la escasa capacidad atribuida al indígena reforzó sus argumentos para mantenerlo sujeto. Difícilmente podría haberse concebido otro tipo de proyecto en el seno de la cultura dominante, sobre todo si tomamos en cuenta que desde los inicios del coloniaje las etnias representaron una alteridad a la que se permitió reproducir sus elementos centrales, siempre y cuando conservara su posición subordinada. En términos generales, a los indios se les consideraba integrantes de una "pobre raza" que "despertaba conmiseración" y cuya "perezosa indolencia", heredada por el mestizaje, sólo podía ser superada a través de una colonización que "inyectara sangre nueva" y "sirviera de es- 


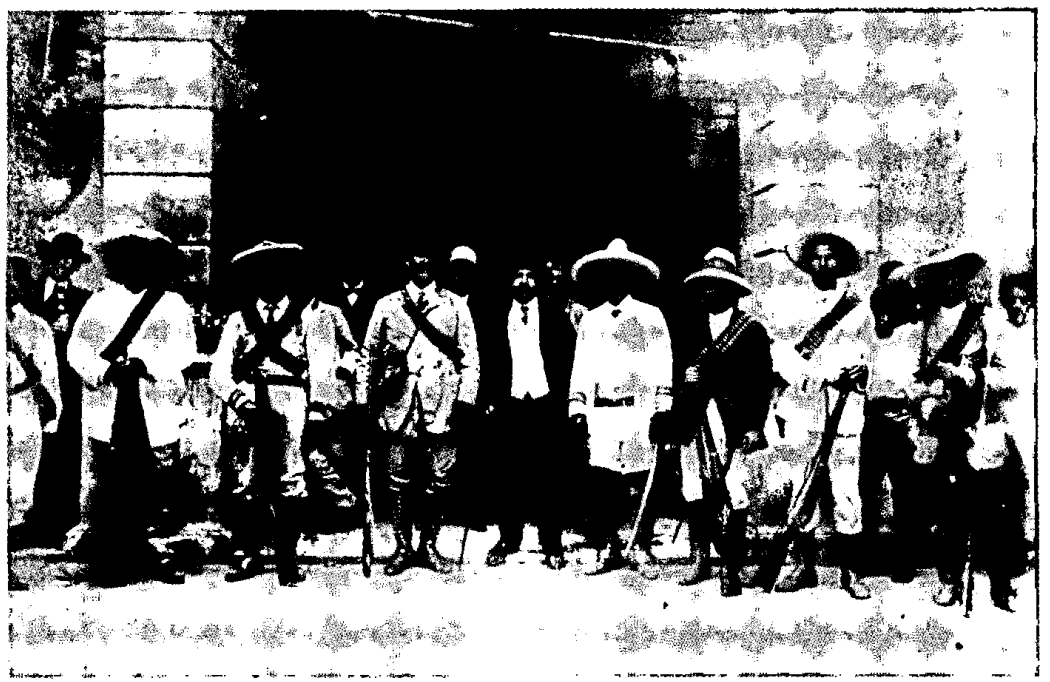

cuela objetiva para destruir sus hábitos de indolente pereza".

El racismo de la época se mezclaba con un espíritu evangelizador que iba más allá del ámbito religioso y formaba parte de los distintos proyectos civiles para organizar a la sociedad decimonónica. En el Reglamento de policía y buen gobierno de 1880 , por ejemplo, se marcaba claramente la concepción del indio como si éste fuera un menor de edad al que había que proteger de sí mismo. Por un lado se restringía la venta de licores embriagantes dentro de sus pueblos (arts. $6^{\circ}, 7^{\circ}$ y $8^{\circ}$ ) y, por

\footnotetext{
${ }^{9}$ El artículo en el que Mallén utiliza tales términos para referirse a los indígenas condensa la ideología predominante entre la sociedad blanca de principios de siglo. Véase Mallén, "Regeneración", 1911, pp. 1-2.
}

el otro, al referirse a los criados se les prohibía (al igual que a los niños), "entregarse en las calles y parajes públicos a juegos que los distrajeran de sus ocupaciones" (art. 11); finalmente, en el rubro de la vagancia se separaba a los indígenas del resto de varones mayores de quince años, y se obligaba a los jefes políticos y presidentes de ayuntamiento a "proporcionar profesión, arte, oficio u ocupación adecuada a su clase o condición a los indígenas que se encotrasen sin su ocupación habitual" (arts. $84,85,86$ y 87$).^{10}$

Aunados a esta posición tutelar que favoreció el control sobre las etnias y que no era por supuesto exclusiva de la sociedad chiapaneca, durante el rabasismo persistieron, e incluso se agudi-

${ }^{10}$ Reglamento, 1880. 
zaron, los conflictos que acompañaron la delimitación de la propiedad agraria.

Aquí vale la pena recordar que desde los inicios del coloniaje la figura de los latifundios tendió a imponerse, aunque originalmente ello no derivó en enfrentamientos mayores porque la demanda de tierra era inferior a su oferta ${ }^{11}$ en una primera etapa los beneficiarios de tal concentración provenían de las regiones alteñas de la entidad, pero después de la independencia, quienes tendieron a erigir grandes haciendas fueron los habitantes de los valles centrales. ${ }^{12}$

Uno de los procesos más importantes que se vivió durante el periodo rabasista fue precisamente el desplazamiento de los hacendados establecidos al amparo de la antigua Ciudad Real, hoy San Cristóbal de las Casas, por parte de las elites asentadas en los valles. El ascenso de estos últimos significó, entre otras cosas, la emergencia de una nueva centralidad político-administrativa y el consecuente traslado de la capital estatal hacia Tuxtla Gutiérrez en 1892.

Con el cambio en la sede para los poderes, Emilio Rabasa rubricó la consolidación del grupo del que él mismo formaba parte. Al parecer Porfirio Díaz lo había elegido para gobernar Chiapas porque en lugar de catalogarlo como miembro de alguna de las camari-

${ }^{11}$ Para mayores detalles sobre este tema véase Pedrero, Haciendas, 1982, pp. 103-105.

${ }^{12}$ Para un buen análisis de los matices que acompañaron estos procesos véase Favre, Cambio, 1984, pp. 67.70; Padilla, "Reforma", 1988, pp. 29-38; García de León, Resistencia, 1985, pp. 153-155. llas locales ${ }^{13}$ lo consideraba capaz de representar a los poderes nacionales; ${ }^{14}$ sin embargo, su actuación y la de sus sucesores se encaminó a fortalecer los intereses vinculados territorialmente con los valles centrales. Los hacendados y comerciantes de la región obtuvieron ventajas diferenciales derivadas de las nuevas condiciones políticas y económicas (el mejoramiento de las vías de comunicación incluido) impulsadas entre 1891 y 1911, etapa durante la cual también se apoyaron empresas como la cafetalera (importante sobre todo en el área del Soconusco) y la maderera (enclavada en la selva). ${ }^{15}$

A pesar de sus aparentes antagonismos, las dos fracciones centrales de la elite que se habían delineado en los albores de este siglo mantenían lazos estructurales y compartían visiones similares de lo que tendría que ser la sociedad chiapaneca. La historiografía ha tendido a identificar a los alteños con los conservadores y a los habitantes de los valles con los liberales; ambas etiquetas corresponden sobre todo a la filiación que en ciertos momentos pudo haber existido con tales banderas en el plano nacional y a los matices en la mentalidad de quienes integraban cada uno de los bandos (tradicionalcerrada y empresarial-progresista, respectivamente).

\footnotetext{
${ }^{13}$ El origen inmediato de Rabasa era Espana, $y$ aunque su familia mantenía vínculos comerciales con Chiapas desde antes de la independencia, se trasladó a Tonalá hasta 1836 . Para mayores datos sobre este personaje véase Glass, México, 1975, pp. 21-23.

${ }^{14}$ Benjamin, Rich, 1989, pp. 40-41.

${ }^{15}$ Ibid., pp. 33-34.
} 
Una de las metas de los grupos que han sido identificados con la corriente liberal era la apertura de espacios vedados para ellos, y por eso sus críticas hacia el modo de vida de la contraparte no incluían un cuestionamiento a fondo de las relaciones de servidumbre o del tipo de organización y manera de funcionar de las haciendas. Sus ímpetus modernizadores estuvieron desde el principio acotados por el espíritu de ganancia, y cuando finalmente impusieron su hegemonía, no dudaron en recurrir a los mismos mecanismos que por años habían utilizado sus contrincantes y que les habían servido para calificarlos negativamente. Está comprobado que liberales y conservadores tendieron a asegurar el flujo de trabajo indigena hacia las haciendas, aun si ello significaba dejar atrás propuestas e incluso decretos que en otro momento habían apoyado. ${ }^{16}$

En el terreno de los hechos tampoco hubo discrepancias a propósito de la concentración fundiaria. Acorde con el objetivo liberal de generar una nueva clase de pequeños propietarios capaz de integrarse a la agricultura de corte capitalista, las tierras comunales se convirtieron en el blanco de una reforma agraria que a la larga se tradujo en el fortalecimiento de la gran propiedad. Si en un principio Rabasa confió plenamente en las bondades de su política ${ }^{17}$ y los resultados iniciales apo-

${ }^{16}$ Véase García de León, Resistencia, 1985 , pp. 153-155; Wassertrom, Class, 1983.

${ }^{17}$ En 1893, un año antes de que se dictara la Ley de Ocupación y Enajenación de Terrenos Baldíos en el plano federal, el gobernador afirmaba: "Repartir los ejidos y vender la parte excedente es sacar ricas y extensas porciones de yaron su certidumbre (para 1910 el número de ranchos se había duplicado con respecto a 1890 y el promedio estatal en cuanto a la extensión de los fundos era mucho menor que el nacional), cinco lustros después admitiría su error. Era ya demasiado tarde: las comunidades perdieron independencia conforme ranchos y haciendas crecían, y el latifundio se consolidó por igual entre hacendados con mentalidad empresarial y hacendados con mentalidad tradicional. ${ }^{18}$

Las coincidencias que pudiesen tener ambos grupos no eliminaban añejas rivalidades fraguadas en la lucha por la hegemonía y matizadas con tintes regionales. El espacio simbólico abierto desde la colonia alrededor de San Cristóbal de las Casas fue horadado al plantearse el cambio de sede para los poderes estatales. Aunque en 1892 la elite surgida al amparo de la antigua Ciudad Real había perdido ya buena parte de su preeminencia económica y política, sus integrantes no estaban dispuestos a aceptar que unos advenedizos hicieran patente la derrota cambiando de lugar la capital.

El escrito en el que los coletos manifestaban su inconformidad por la medida, resume el sentimiento de despojo

terreno del abandono en que hoy se encuentran y entregarlas al trabajo; es negarlas a la explotación inconsiderada e improvisada del que usufructa destruyendo lo que nada le cuesta, y concederla a la prudente mesura del propietario que no derriba el árbol sino para sembrar la semilla." Además de éstos, otros conceptos en el mismo sentido pueden encontrarse en el informe que ese año rindio ante el Congreso, véase Discurso, 1893, pp. 9-10.

${ }^{18}$ Benjamin, Rich, 1989 , pp. 48-50. 
que se había despertado en ellos. ${ }^{19}$ Los argumentos para evitar que Tuxtla asu. miera su nueva investidura se remontaban a la fundación de la Ciudad Real en 1528 , y se resaltaba su papel como eje del proceso de poblamiento de los valles que la circundaban. El mensaje era claro, estos últimos debían a su antigua matriz la existencia misma, y a pesar de todo se volteaban contra ella.

Los Cabrera, los Gordillo, los Escandón, los Argüello, los Albores, los Domínguez, los Culebro, los Román, los Rivera, los Aguilar, los Ruiz, los Coello, los Villatoro, los Guillén, los Mandujano, los Figueroa, los Velasco, los Gorriz, los Tovilla, los Cancino, los Borraz, los Ocampo, los Montes, los Peña, los Cristiani, salieron rumbo a Comitán y San Bartolomé para explotar los ganados caballar, vacuno y lanar; los Guerra, los Camas, los Flores, los Córdova, los Coutiño, los Zapata, los Escobar, los Grajales, los Aguilar, se dedicaron a la industria azucarera, la ganadería y el cultivo del añil en Chiapa de Corzo; en Tuxtla se establecieron los Palacio, los Zorrilla, los Sanjuán, los Camacho, los Flores, los Madrigal, los González, los Balboa, los Moguel, los Figueroa, los Cruz, los Bustamante, los Marini, y "de entre estas familias los más acomodados crearon las mejores haciendas de los valles de Jiquipilas y Cintalapa, dedicándose con especialidad a la ganadería y al cultivo de la grana y el índigo". El recuento genealógico (que incluye otros lugares y familias además de los aquí citados) sacaba a relucir el origen alteño de quienes buscaban alterar equilibrios territo-

\footnotetext{
${ }^{19}$ Traslación, 1892.
}

riales de poder establecidos desde la colonia. ${ }^{20}$

En realidad, según afirmábamos antes, dichos equilibrios ya se habían desbaratado. El cambio de sede de la capital se limitió a confirmar hechos consumados, y representó la formalización de la nueva orientación geográfica de la entidad: mientras San Cristóbal se encontraba en la ruta comercial hacia Guatemala, Tuxtla abría la puerta que conducía a México. ${ }^{21}$ Sin embargo, los coletos estaban convencidos de la legitimidad que asistía a sus derechos para conservar el control sobre la centralidad político-administrativa, e incluso se involucraron en una guerra con el propósito de defender su postura. ${ }^{22}$

En septiembre de 1911, al tiempo que León de la Barra encabezaba un gobierno federal interino, coletos y tuxtlecos formaron sendos grupos armados y, utilizando como pretexto los resultados en las votaciones para integrar la XVII Legislatura local y para elegir al gobernador constitucional del estado, llevaron al terreno del combate abierto rencillas y antagonismos largamente incubados.

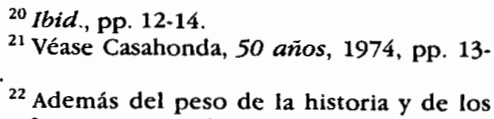

${ }^{21}$ Véase Casahonda, 50 años, 1974, pp. 13-

${ }^{22}$ Además del peso de la historia y de los 14. beneficios que a lo largo de la misma había brindado San Cristóbal a Chiapas, la posibilidad de colonizar las tierras bajas inclusive, se argumentaron razones de toda índole: desde la geografia hasta la importancia de controlar de cerca a los indígenas (mayoritariamente concentrados en los Altos), pasando por la riqueza generada en su interior y la ilegalidad de lo que se consideraba un acto autoritario de Rabasa. Véase Traslación, 1892, pp. 1-32. 
Sin detenernos demasiado en el detalle de los hechos inmediatos que precedieron al conflicto, vale la pena recordar que éste se enmarcó en la evidente dificultad del poder central para resolver la transición del porfiriato al maderismo. Pugnas locales se sumaron a los problemas que se vivían en la ciudad de México, y aunque de acuerdo con el Tratado de Ciudad Juárez, desde la capital del país se podía recomendar candidatos para las gubernaturas a las legislaturas de los estados, cuando Emilio Vázquez Gómez (secretario de Gobernación) sugirió a un antiguo opositor del rabasismo (Eusebio Salazar y Madrid), pasó por alto que la mayoría de los diputados, electos con anterioridad, no aprobarian a un enemigo del régimen que ellos representaban.

Por último, tuvieron los señores diputados y el gobernador una última entrevista en uno de los salones de palacio, y éste les suplicó que le aceptasen su renuncia, a lo cual accedieron atendiendo a razones de conveniencia enteramente personal para el señor Trejo; pero cuando abordó la cuestión del nombramiento del nuevo interino, el señor doctor Martínez Baca, llevando la voz por sus colegas, y en una peroración neta y dura, manifestó que la Cámara estaba dispuesta a no admitir indicaciones de ningún género [consignas] y a no aceptar al designado por la Secretaría de Gobernación, pues habían determinado obrar con la más absoluta libertad. Desde ese momento el gobernador no volvió a hablar más de candidatos y esperó el desarrollo de los acontecimientos [...] En la Cámara todo pasó como se había previsto; la candidatura del ingeniero Gordillo León, que ya estaba casi aprobada de antemano, fue someti- da al escrutinio secreto y obtuvo la unanimidad. La elección del señor Gordillo León es obra exclusiva de la legislatura, sin que los señores diputados hayan atendido ninguna influencia exterior. ${ }^{23}$

Cuando en San Cristóbal se enteraron de que Gordillo León sería el gobernador interino, decidieron nombrar a Manuel Pineda para el mismo cargo. La existencia de dos gobiernos paralelos constiuía una invitación abierta a tomar las armas, y mientras en la capital de la entidad se formaba el batallón Los hijos de Tuxtla, en los Altos se ponía en pie de guerra a la población. Vázquez Gómez intentó desactivar el conflicto y propuso sustituir a Gordillo Léon por Policarpo Rueda, pero el cambio, aceptado por el Congreso local, duró poco tiempo, y Manuel Rovelo Argüello (recomendado por Alberto García Granados después de ocupar el Ministerio de Gobernación en lugar de Vázquez Gómez) fue quien finalmente se hizo cargo del ejecutivo chiapaneco.

Las presiones y enfrentamientos que se desataron por un cargo de tipo interino, en parte se explican porque los dos principales grupos en pugna buscaban asegurarse la mayoría en los comicios que llevarían a la integración de la XXVII Legislatura local (responsable de mantener la capital en Tuxtla o de regresarla a San Cristóbal) y, por supuesto, en la votación para gobernador constitucional del estado. Final-

23 "El gobierno interino de Chiapas. La legislatura del estado no atendió la indicación de la Secretaría de Gobernación y votó un candidato a su satisfacción", El Heraldo de Chiapas, vol. vı, núm. 52, 2 de julio de 1911, Tuxtla Gutiérrez. 
mente la responsabilidad de supervisar dichas elecciones recayó en Rovelo Argüello, quien no logró legitimar el resultado de las mismas.

Para el partido ganador se trató de un proceso sin anomalías, ${ }^{24}$ mientras que para la oposición fue un fraude abierto. ${ }^{25}$ En septiembre de 1911 el jefe de armas de San Cristóbal, Juan Espinoza Torres, encabezó una rebelión que desconocía a los poderes estatales. Los insurrectos daban un plazo de 24 horas para que se disolviera el Congreso y el ejército quedara a su disposición, al tiempo que buscaban inclinar la balanza a su favor con el apoyo federal. Desde el centro se apoyó sin embargo al gobierno establecido en Tuxtla, de allí que la lucha militar durara poco. ${ }^{26}$

Los alteños eran superiores numéricamente hablando, pero la mayor parte de sus fuerzas estaba conformada por indígenas (alrededor de 8000 ), los cuales, al igual que los ladinos que los acompañaban, carecían de armas e instrucción militar. Al mando del contingente chamula se encontraba Jacinto Pérez, apodado "Pajarito"; por las descripciones que de él se han hecho, se trataba de un personaje de baja estatura, con un color de piel un poco más claro que los de su raza, de actitud humilde y siempre vistiendo un traje regional. Su simple presencia imprimió sesgos étnicos al conflicto, y aunque desde un principio los líderes del mo-

\footnotetext{
${ }^{24}$ La versión de este grupo puede encontrarse en Espinoza, Rastros, 1912, pp. 35-41.

${ }^{25}$ La versión de este grupo puede encontrarse en Martínez, Últimos, 1912, pp. 26-27.

${ }^{26}$ Benjamin, "Revolución", 1980, pp. 87-89.
}

vimiento sancristobalense capitalizaron los dones carismáticos de este líder, el temor de que aprovechara su poder para iniciar una nueva guerra de castas se mantuvo hasta su fusilamiento tres años después. ${ }^{27}$

De acuerdo con la versión tuxtleca, el obispo Francisco Orozco y Jiménez era el principal responsable de haber abierto la caja de Pandora, al promover la participación chamula en la guerra de 1911. Aunque el prelado siempre negó los cargos, en la capital de la entidad se le acusó de haber incitado a la rebelión y de haber persuadido a los indígenas para que se unieran a ella.

\section{ACTORES Y ESPECTADORES}

Cuando el conflicto armado entre las dos principales regiones del centro de Chiapas llegó a su fin, previa intervención de las fuerzas federales, ${ }^{28} \mathrm{el}$ obispo de San Cristóbal de las Casas (Francisco Orozco y Jiménez) había consolidado su posición como figura importante dentro de la escena política estatal. Desde el momento mismo de su consagración (en 1902) intentó mantener buenas relaciones con los intey 94.

${ }^{27}$ Véase Moscoso, Jacinto, 1972, pp. 24-25

28 "Los tratados de paz hicieron perder a los sancristobalenses el recurso del estado de sitio; los tratados de paz diéronle legalidad al señor Rovelo puesto que fue reconocida su autoridad", escribía en 1912 el general Eduardo Paz, quien, al mando del batallón 19, representó a las fuerzas federales y derrotó a los insurrectos, obligando al reconocimiento del gobernador a cambio de una amnistía general. Paz, Cuestión, 1912, pp. $42-43$. 


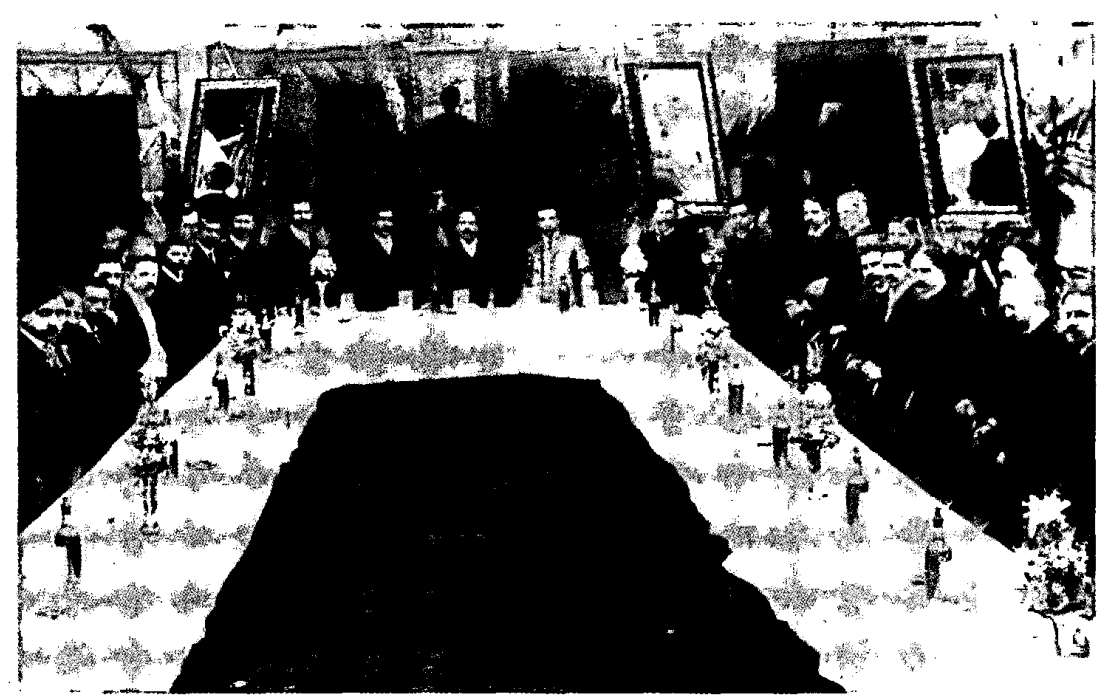

grantes de la elite chiapaneca que ocupaban diputaciones y senadurías en la capital del país. Aunque los periódicos no consignaron el hecho, al parecer los invitó al acto en el que se le nombraba obispo de Chiapas. ${ }^{29}$

Las peculiaridades del escenario al que se lo enviaba restaron sin embargo eficacia a las dotes diplomáticas de Orozco y Jiménez. Lo esperaba un am. biente enrarecido por pugnas entre grupos de poder regionales que buscaban recuperar en un caso y consolidar en el otro, su papel hegemónico dentro de la estructura social. Dado el peso que tradicionalmente había tenido la Iglesia, su alianza con cualquiera de ellos se traducía en capital político; en

\footnotetext{
29) Véase, Camberos, Francisco, 1966, pp. 108-109.
}

este sentido, a pesar de que el discurso liberal -con sus tintes anticlericaleshabía tenido eco sobre todo en Tuxtla, es probable que la identificación del obispo con la elite coleta haya molestado a los adversarios de esta última.

La decisión de mantener la sede de la diócesis en San Cristóbal era congruente con la simpatía que pudo haber sentido el prelado hacia la idiosincrasia alteña, pero contravenía los esfuerzos realizados poco antes para cambiar formalmente la orientación espacial del poder. Por otro lado, ajenos a los dimes y diretes entre los que se desenvolvía la vida de las elites, los indígenas representaban un sector importante dentro de la feligresía de Orozco y Jiménez.

El tata cura de 38 años llegaba a Chiapas después de trayectorias que 
incluían contactos esporádicos con el México indio. Nacido en una zona que durante la colonia había servido de frontera contra las tribus chichimecas (Zamora, Michoacán), se desenvolvió en ambientes más bien hispanizados, y realizó parte de sus estudios en Roma y la ciudad de México. A partir de 1902 sus esfuerzos se encaminarían a abrir las puertas de un mundo nuevo y en cierto sentido ajeno a lo vivido.

Lo primero que hizo fue seguir la misma ruta que fray Bartolomé de las Casas y los frailes dominicos habían utilizado siglos atrás, trayectoria que implicaba detenerse en Chamula antes de llegar a San Cristóbal. El recibimiento que se le brindó auguraba buenos momentos, ya que el líder local (Jacinto Pérez, "Pajarito") había ordenado colocar arcos florales para adornar el pueblo; a partir de ese momento Orozco adquirió fuerza entre la comunidad, y cada dos semanas bajaban indígenas cargados de incienso para obsequiarle. Además, siempre que "Pajarito" viajaba a San Cristóbal lo visitaba y le llevaba a su vez incienso envuelto en papel blanco. El poder del sacerdote en la zona llegó a tal grado, que "Pajarito" y sus seguidores eran conocidos como los rezadores. ${ }^{30}$

En 1904, el obispo encabezó una peregrinación a la Basílica de Guadalupe, y aprovechó el momento para solicitarle a Porfirio Díaz mayor justicia hacia los indios de Chiapas. Después de escucharlo, el presidente ordenó a su secretario que preparara un decreto para que los representantes fede-

\footnotetext{
${ }^{30}$ Véase Smithsonian, pp. $37+38$.
}

rales y estatales trataran con justicia a los indios de la entidad. ${ }^{31}$ Éste y otros actos incrementaron la popularidad de Orozco entre los indígenas y reforzaron su capacidad de control sobre un grupo al que los ladinos habían utilizado y cuya supuesta barbarie habían temido por años.

A la par que su relación con la comunidad se hacía más fuerte, las reticencias de ciertos sectores contra la figura del religioso también se incrementaron. En una ocasión sus enemigos trataton de detenerlo al grito de "muera Chamula", ${ }^{32}$ sin embargo, quizá los momentos más conflictivos de su estancia en Chiapas hayan girado alrededor de la guerra de 1911. La acusación de haber instigado la revuelta pudo o no contar con bases reales que la sustentaran, ${ }^{33}$ pero tuvo tal eco que se reprodujo en las prènsas estatal y nacional. $^{34}$

${ }^{31}$ Ibid., pp. 38-39.

${ }^{32} \mathrm{La}$ anécdota completa del suceso, que tuvo lugar a principios de 1911, incluye la actitud ingeniosa del párroco, que lo salvó fingiendo una supuesta ida al baño, cuando en realidad acababa de cargar al obispo (haciéndose acreedor a una hernia que le acompañaría de por vida) y pasarlo del otro lado de una cerca para evitar su captura.

${ }^{33}$ Las fuentes que permitirian determinar el grado de participación del obsipo son insuficientes. Encontramos testimonios de ambos bandos que aseguran o bien un involucramiento directo, o bien una neutralidad absoluta, pero, en todo caso, ninguna de las dos versiones aporta todos los elementos para tomarla y desechar la otra.

${ }^{34}$ Véase El Imparcial, 8, 9 y 10 de julio de 1911; La Patria, 12 de julio, 16 de agosto de 1911; El Democráta Mexicano, 14, 15, 17, 19 , 28 de julio, de 1911, y El Heraldo de Chiapas, 6 de julio de 1911. 
Desde el inicio la postura del obispo fue defendida en San Cristóbal. Un grupo de coletos respaldó abiertamente al prelado a través de volantes en los que, a título de Protesta Pública, se establecía la espontaneidad del movimiento y se negaba la intervención en él de un alto dignatario de la Iglesia. Algunos de los argumentos utilizados para legitimar la reacción alteña fueron los siguientes:

He aquí la verdad de los hechos. A iniciativa del mayor del Ejército Maderista de Ocosingo, don José Castellanos, de don Deifilio Martínez Rojas y de algunos otros señores de esta ciudad -San Cristóbal- se procedió a la formación de un cuerpo de voluntarios dispuestos a secundar la política del nuevo gobierno. Al saberse que la legislatura del estado se rehusó a nombrar al gobernador interino designado por la Secretaría de Gobernación, el pueblo de San Cristóbal se reunió en masa y, desconociendo al gobernador provisional con residencia en Tuxtla Gutiérrez, nombrado por el llamado Congreso, proclamó al señor don Manuel Pineda para gobernador provisional, con residencia en esta ciudad. Desde entonces hubo que pensar en la defensa de esta ciudad y de los departamentos que se adherían. Con tal motivo se organizó un cuerpo de indígenas, quienes con la mayor espontaneidad se habían ofrecido de antemano para el sostén del nuevo gobierno. ${ }^{35}$

Quienes suscribían el documento (Lindoro Castellanos encabezaba una

${ }^{35}$ Protesta Pública, San Cristóbal de las Casas, 10 de julio de 1911. Archivo personal de la familia Guillén Castañón. lista de 160 firmas respaldadas, de acuerdo con una anotación, por otras $1200)$ aseguraban que los indios que habían recorrido la ciudad lanzando vivas a Madero y a Manuel Pineda estaban dispuestos a sostener su total autoría y responsabilidad por actos lejanos a cualquier espíritu sedicioso y motivados más bien por el "patriotismo y virilidad de los buenos hijos de la ciudad". A través del volante la sociedad alteña protestó también contra los periódicos nacionales y estatales que reproducían la mala imagen de Orozco y Jiménez, al presentarlo como el cabecilla de una banda de revoltosos. ${ }^{36}$

En favor del obispo salieron otras tantas publicaciones estatales y nacionales (destacan El Tiempo, El País, El Amigo de la Verdad desde la ciudad de México; La Esperanza, La Voz de Chiapas, La Libertad del Sufragio y La Verdad, dentro del propio estado; y otras como El Domingo de Durango o La Revista de Mérida). Además del apoyo de sus feligreses y simpatizantes, Orozco recibió un ocurso de desagravio de parte del clero. El 17 de julio el gobernador de la sagrada mitra (L. Pacífico González), hizo entrega del documento respectivo en el que se asentaba la imposibilidad de que el prelado hubiese estado presente en las movilizaciones, dado que realizaba trabajo pastoral en otros pueblos; asimismo se mencionaban sus esfuerzos en favor del progreso moral y material de toda la diócesis y se resaltaba su deseo, manifiesto en las oraciones públicas que había ordenado, de "alcanzar de Dios

${ }^{36} \mathrm{Ibid}$. 


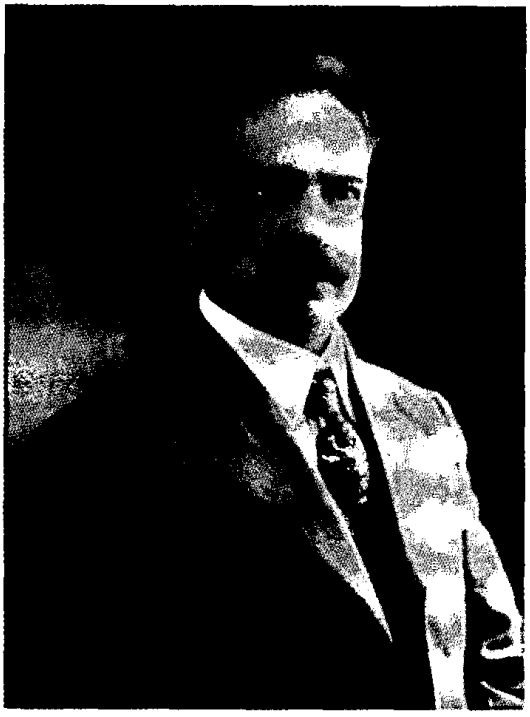

Nuestro Señor la paz y perfecta unión de los pueblos, anhelando para todos ellos, sin distinciones ni preferencias, la prosperidad y el bienestar". ${ }^{37}$

Ias muestras de adhesión se multiplicaban conforme el bando contrario insistía en culpar al obispo. Desde telegramas, protestas y comunicaciones, hasta cartas abiertas dirigidas al presidente (León de la Barra) y al gobernador (Policarpo Rueda), presionaron para que oficialmente se reivindicara la labor de Orozco. Por cálculos políticos o porque en realidad estaba convencido de ello, Rueda envió respuestas en el sentido que los seguidores del obispo deseaban y, además de calificar de 193-194. "absurdas y escandalosas" las versiones que hacían aparecer al prelado "como protagonista de los sucesos ocurridos en esa ciudad", lamentaba que hubiese personas tan malintencionadas como para pretender "dividir más y más a dos pueblos hermanos", 38

En medio de las disputas que se habían generado alrededor de su figura y a raíz de los enfrentamientos armados entre los voluntarios de San Cristóbal y los hijos de Tuxtla (septiembre de 1911), el propio obispo envió tres cables al presidente. En el primero de ellos solicitaba su intervención para evitar una inminente ruptura de hostilidades entre los partidarios de ambos bandos. En el segundo hablaba de que su autoridad eclesiástica se hallaba disminuida y de que todos los medios se habían agotado, por lo que se requería de una rápida y urgente intervención federal. Por último, al día siguiente de haber sacado un edicto en el que imploraba por la paz, envió la tercera comunicación manifestando su sorpresa por el trato recibido en la prensa y resaltando que su trabajo con los chamulas carecía de cualquier ambición política. ${ }^{39}$

En la medida en que la guerra se resolvió en favor de los tuxtlecos, la posición de Orozco se vio afectada. Es verdad que el espacio que servía de escenario a su labor giraba fundamentalmente alrededor de San Cristóbal, pero no puede olvidarse que la sede de los poderes seguía siendo Tuxtla y que en esta última la imagen del obispo se había deteriorado.

${ }^{38}$ Ibid., p. 195.

39 Véase Smitbsonian, p. 41. 
Los niveles de rechazo hacia el prelado afloraron un año más tarde, cuando se supo que Flavio Guillén lo había invitado para oficiar su boda. Guillén había asumido el cargo de gobernador interino de Chiapas a petición expresa de Madero, y para algunos representaba la posibilidad de perpetuar el rabasismo. A su llegada a la entidad (enero de 1912), el gobernador constitucionalmente electo era Reynaldo Gordillo León, quien había sido declarado triunfador en los comicios realizados dos meses antes.

Los resultados electorales habían sido sin embargo cuestionados por los simpatizantes del candidato que representaba los intereses alteños (José Antonio Rivera G.), ${ }^{40}$ de allí que, para evitar enfrentamientos como los que meses antes se habían escenificado en el estado, el presidente decidiera enviar a un personaje en el que confiaba plenamente y al que desde tiempo atrás le unía una buena amistad.

De acuerdo con su trayectoria, Flavio Guillén parecía tener mayores puntos de contacto con el grupo tuxtleco. Nacido en Zapaluta (hoy Trinitaria), realizó parte de sus estudios en Guatemala, y aunque nunca concluyó las carreras universitarias que le atraían (derecho y medicina), dedicó buena

\footnotetext{
${ }^{40}$ El conteo oficial otorgó 285 votos a Gordillo y 242 a Rivera, pero, de acuerdo con la oposición, a Gordillo le correspondian 292, mientras que Rivera se quedó con 320 . El desglose de los resultados por departamentos que en ambos casos se hizo puede verse en Espinoza, Rastros, 1912, p. 223, y en Martínez, Últimos, 1912, p. 40.
}

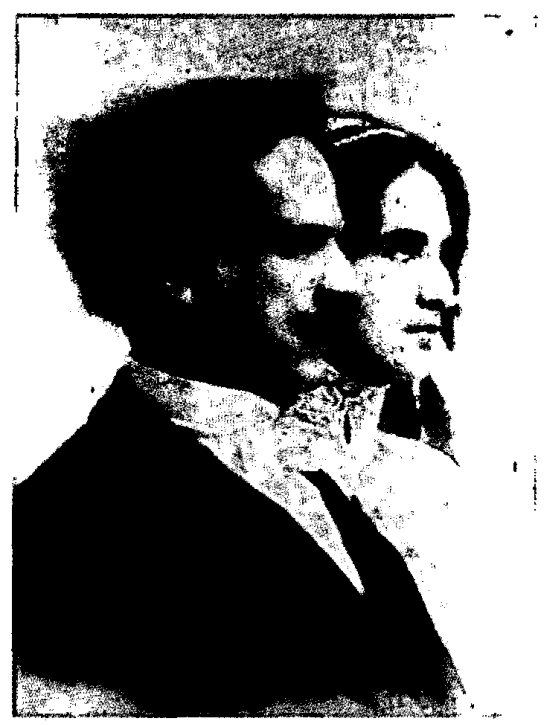

parte de su vida a incrementar una erudición que le hacía sobresalir y que procuró transmitir a través de la docen. cia y del periodismo. Se trataba de una figura polifacética que lo mismo daba clases de ciencias exactas y de gramática, que presidía la Sociedad Mexicana de Temperancia, o era vicepresidente de la Sociedad de Estudios Psíquicos Central [sic]; al tiempo que participaba en congresos espiritistas, se inscribía en la logia masónica Ignacio Ramírez e ingresaba a algunas agrupaciones de carácter científico (Sociedad Astronómica de Méjico [sic]; Academia de Ciencias; Sociedad de Investigaciones Psicoquímicas, y Sociedad Mejicana de Plasmogenia [sic]) o literarias (Sociedad Literaria Manuel Gutiérrez Nájera; So- 
ciedad Literaria Arts et Labor, y Sociedad de Escritores y Artistas). ${ }^{41}$

Durante su estancia en la ciudad de México (a partir de 1901 y hasta 1912 vivió en la capital, con un intervalo entre 1909 y 1910 que pasó en Chiapas) conoció a Emilio Rabasa:

De nombre me era conocidísimo. Nada menos que de niño yo me leía, es decir, me bebía la hermosa prosa de sus lindas novelas, las mejores (para mí) que se han escrito en la América española. Coterráneo mío, pues chiapense y amable y fino de suyo, me simpatizó fuertemente en el instante de la presentación y le ofrecí visitarlo al día siguiente en su casa de la [ilegible] de Sta. Maria la Ribera. Hablamos de todo, pero el tema que más prefirió y donde más me hacía hablar era el de física, con asombro y contento mío que gozo infinito cuando encuentro rarísima vez otro que ame esta ciencia como yo. Este cariño a la física fue entonces el lazo más fuerte para la amistad de don Emilio. Pronto la intimamos y desde entonces me ha sido la amistad más útil de México, no tanto material como moralmente. Pero esto no es negar que me ayudó en la lucha por la vida. Por influencia de él conseguí mi primer empleo a los ocho meses de buscarlo y cuando ya no tenía sino deudas. ${ }^{42}$

La amistad entre Flavio Guillén y Rabasa ya había motivado comentarios negativos, cuando en junio de 1911 se convocó a la colonia chiapaneca residente en la ciudad de México para que

${ }^{41}$ En otro trabajo ya hemos abundado sobre la trayectoria y actuación de Flavio Guillén. Véase Guillén, Maderismo, 1994.

${ }^{42}$ Guillén, Hijos, 1914 , p. 83 . Archivo personal de la familia Guillén Castañón. propusiera candidatos al gobierno estatal. La reunión tuvo lugar en el teatro Tívoli del Eliseo, y Guillén derrotó por una amplia mayoría (67 contra 28 votos) a Salazar y Madrid; sin embargo, como veíamos antes, este último nombre fue el que finalmente se sugirió para ocupar el cargo. Todavía con la certidumbre de que el acto del Tívoli tendría mayor peso en la definición de la persona que se impulsaría ante el Congreso local, ${ }^{43}$ Jesús Matínez Rojas intentó disuadir a la audiencia en contra de don Flavio, "tachándolo de rabasista y por lo mismo corralista, y de haber perdido su nacionalidad en Guatemala". ${ }^{44}$

Don Flavio nunca negó tales vínculos, y ello contribuyó a la hostilidad inicial de los grupos alteños, quienes consideraron su nombramiento como un triunfo de los científicos. A pesar de todo, el nuevo gobernante se abstuvo de inclinar la balanza en favor de los intereses tuxtlecos; desde un principio sus actos se guiaron por el lema conciliación y concordia entre bermanos, y ello se reflejó tanto en el debilitamiento de la influencia de don Emilio dentro de la entidad, como en la acentua-

${ }^{43}$ En principio todo hacía suponer que la reunión del Tivoli inclinaría la balanza. Incluso, una vez conocidos los resultados, Madero declaró que "no había hablado aún sobre el particular con el ministro de Gobernación; pero ya se había fijado en la mayoría de votos que obtuvo el señor Flavio Guillén sobre los tres candidatos restantes y había tomado nota de ello". El Heraldo, sin fecha, México. Archivo personal de la familia Guillén Castañón.

4í "El primer ensayo de democracia. Chiapas va camino del progreso", La Patria, sin fecha, México. Archivo personal de la familia Guillén Castañón. 
ción de la lealtad de Chiapas hacia las instancias federales. ${ }^{45}$

Un mes antes de su enlace matrimonial, Flavio Guillén era respaldado por la misma persona que el año anterior se le había opuesto tajantemente en el Tívoli. A través de un manifiesto público, Jesús Martínez Rojas reconocía que el gobernador había actuado en bien del pueblo, "aconsejado por la justicia y la imparcialidad". Aclaraba que no había contraído ningún compromiso político con aquél, pero también mencionaba que habian reanudado su amistad y que confiaba en el cumplimiento de las promesas hechas para bien del pueblo. El cambio en los juicios de Martínez Rojas era explicado así:

La candidatura del señor Guillén fue propuesta entonces por la liga de los partidos de Rabasa-Castillo y si hubiera entonces el señor Guillén venido a Chiapas, tenía por compromiso que ser deferente y servir al partido político que lo había elevado con su voto a la primera magistratura, así es que debiera ser la continuación del rabasismo, o sea del caciquismo en Chiapas. Hoy el señor Guillén ha venido al estado como comisionado del señor Madero, jefe de la revolución triunfante, y la legislatura lo ha nombrado gobernador del estado. Natural es que el señor Guillén, como amigo del señor Madero, trate de implantar en la práctica y desarrollar los principios de la revolución, cumpliendo así con las promesas del Plan de San Luis en lo concerniente al régimen interior del estado, que son los ideales que perseguimos los del Partido Chiapaneco Popular Progresista; nada importa que Guillén haya sido o sea amigo de

${ }^{45}$ Benjamin, Rich, 1989, pp. 112-113. los Rabasa; a éstos no les debe el puesto que ocupa, y tiene que ser antes consecuente con sus principios y su adhesión al señor Madero, que continuador del caciquismo en Chiapas. Debemos juzgar al señor Guillén sin prejuicios, sin mala prevención por sus amistades particulares; sus propios actos serán los que demuestren el desarrollo de su política; aunque fuera un verdadero rabasista nada importaría esto, viniendo a destruir el caciquismo en Chiapas obra de Rabasa y a hacer prosperar la obra de la revolución. ${ }^{46}$

\section{LA BODA}

El cambio de imagen que al parecer logró don Flavio entre los coletos, puede también deducirse a partir de la anuencia de Orozco y Jiménez para oficiar la misa en la que el gobernador contraería nupcias. Este último se había comprometido con Isabel Castañón, quien formaba parte de una de las principales familias tuxtlecas. Famosa por su belleza, la novia representaba al grupo de chiapanecos que se asentaron en los valles centrales y consolidaron su posición después de la independencia.

La familia Castañón reside ahora toda en el departamento de Tuxtla; es de origen español, noble, pues el fundador del apellido en Chiapas tenía escudo nobiliario; en Comitán todavía se usa entre los viejos el refrán: no es ningún

${ }^{46}$ Al público. Manifiesto del Lic. Jesús Martínez Rojas, San Cristóbal L. C., 4 de febrero de 1912. Archivo personal de la familia Guillén Castañón. 
Castañón, para indicar que alguno es plebeyo. $^{47}$

Vale la pena aclarar que los parámetros con los que a principios de siglo se medía el estatus variaban dependiendo de la región. Quienes habían poblado los valles eran, a los ojos de los alteños, advenedizos que carecían de prestigio aun cuando hubiesen acumulado tierra y dinero. Después de varios siglos de coloniaje, los habitantes de San Cristóbal podían trazar. su línea genealógica sin salir de la entidad; el abolengo iba de la mano de raíces establecidas en la antigua Ciudad Real. Centros urbanos de menor tradición (Comitán, Tuxtla, Chiapa de Corzo, por ejemplo) eran producto de migraciones más recientes y, por tanto, los criterios para identificar a las elites recuperaban la ascendencia española.

En este marco, la fusión de los apellidos Guillén de Comitán y Castañón de Tuxtla, cumplía con los requisitos sociales tendientes a reproducir, cohesionar, y fortalecer a dichas elites. ${ }^{48}$ Tal vez las posesiones de un lado (Castañón) eran superiores a las del otro, pero en el momento de la boda el gobernador concentraba un poder político que compensaba cualquier desequilibrio económico.

Aunque los contrayentes habían tenido un encuentro casual durante el Bai-

${ }^{47}$ Guillén, Hijos, 1914, p. 163.

${ }^{48}$ El abuelo materno de don Flavio (de apellido Ancheytia) provenía de Zaragoza, España, y se dedicaba a la escultura y platería; mientras que el abuelo paterno era agricultor y propietario en la zona (lo mismo que su padre). Ibid., pp. 10-14. le de Reelección (diciembre de 1909), sería tres años después cuando se reencontrarían en la finca El Trapiche de Carlos Castañón. Doña Isabel vivía con este último, y a él se dirigió don Flavio "pidiendo permiso de visitar a su sobrina, declarándole con qué fin, como se estila en Chiapas". Después escribió a don Rafael, padre de la novia, quien "vivía en su finquita de campo Río Dulce, no lejos de Tuxtla". 49

A partir de ese momento se sucedieron acontecimientos inesperados en el seno de la familia Castañón. Por razones que desconocemos, la esposa de don Carlos se opuso al enlace, y la novia tuvo que cambiar de residencia antes de que éste se realizara; otra hermana de don Rafael (Hermelinda) la acogió, y de su casa salió el día de la boda. ${ }^{50}$

Los conflictos personales que rodearon el matrimonio Guillén-Castañón dividieron a la familia y razones de todo tipo salieron a relucir: de un lado se aducía la falta de agradecimiento de quien había sido tratada como hija y la deshonra que su insubordinada actitud infligía sobre sus protectores, mientras que del otro se argumentaban sentimientos de envidia e interés por conservar un apoyo eficiente en el manejo de todos los aspectos domésticos. ${ }^{51}$ Frente a tales desencuentros, desde la presidencia de la república se trató, infructuosamente, de allanar el camino; el propio Madero solicitó a Carlos Castañón que lo representara en el evento,

${ }^{49}$ Ibid., pp. 162-163.

${ }^{50}$ Entrevista a Carlos Castañón Morel. Tuxtla Gutiérrez, marzo de 1990.

${ }^{\text {s1 Ibid. }}$ 


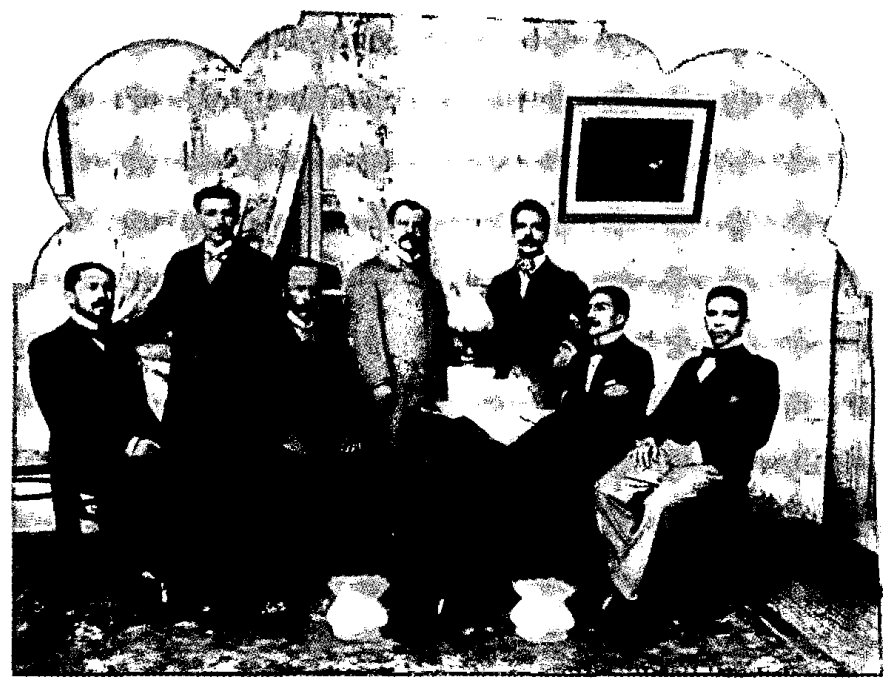

pero este último se negó y finalmente no asistió. ${ }^{52}$

En un principio el gobernador pensaba casarse sólo civilmente "por no ser católico ni hipócrita para fingir creencia en actos que no se creen". Lo detenía sobre todo el obstáculo de la confesión auricular que le parecía "humillante e inmoral", pero Orozco y Jiménez lo convenció para que "obsequiara yo a mi novia con las solemnidades del rito eclesiástico". 53

El obispo de San Cristóbal se mostró muy complacido ante la decisión

52 Carta de Carlos M. Castañón a Francisco I. Madero, Tuxtla Gutiérrez, octubre 7 de 1912 , Archivo General de la Nación (en adelante AGN), Fondo Francisco I. Madero, caja 14, exp. 337, f. 010866.

${ }^{53}$ Guillén, Hijos, 1914, p. 163. de Guillén de celebrar su matrimonio también por la Iglesia. Ambos personajes sabían que, más allá de las repercusiones sociales o de conciencia derivadas del acto religioso, la posibilidad de que Orozco se trasladara a Tuxtla y otorgara la bendición nupcial escon. día simbolismos políticos importantes. Desconocemos la carta de invitación enviada por el gobernador, pero de la respuesta a la misma se desprende la clara conciencia de las dificultades potenciales que conllevaba una visita del obispo a la capital de la entidad.

Las consideraciones que me hace usted para desvanecer dificultades que pudiera tener yo para determinarme a acceder a sus deseos de ir a bendecir su enlace personalmente en esa localidad, al agradecérselas, le manifiesto que de ninguna manera las hubiera tenido en 
cuenta, por parecerme infundadas, $y$ que nunca las hubiera tenido en cuenta en el cumplimiento de mis obligaciones. Me ha bastado pues saber sus deseos, para violentar y anticipar mi viaje a esa ciudad, cuya visita me había determinado hacer luego que comenzaran aquí los fríos, lo mismo que de otras poblaciones. ${ }^{54}$

La boda brindaba un buen pretexto para consolidar el trabajo realizado por el gobernador en aras de la "conciliación y concertación entre hermanos". Ya había conseguido mejorar su imagen en San Cristóbal y había tendido puentes amistosos con sus antiguos enemigos. El que Orozco se dirigiera a él con afecto (otros párrafos de la carta son ilustrativos en este sentido) y le otorgara su bendición en un acto público, hablaban de cierta tregua que podía ampliarse más allá de sus vínculos personales.

El obispo, por su parte, necesitaba mejorar una posición debilitada a raíz de la guerra de 1911 , de allí que decidiera aprovechar la ocasión para limar asperezas con los sectores de su feligresía que lo culpaban de haber instigado a los chamulas y apoyado a los alteños. Era claro que, dada su posición jerárquica dentro de la estructura eclesiástica, tenía que desvanecer los cargos de parcialidad que se le imputaban y fortalecer una legitimidad que le permitiera llevar adelante su labor pastoral y política. Con la.idea de sacar

\footnotetext{
${ }^{54}$ Carta de Francisco Orozco y Jiménez, obispo de Chiapas, a Flavio Guillén, gobernador del estado, San Cristóbal, L. C., octubre 3 de 1912. Archivo personal de la familia Guillén Castan̄ón.
}

el mayor jugo posible a la visita, decidió incluso realizar en Tuxtla una celebración que tradicionalmente había sido importante para San Cristóbal.

No será por demás manifestarle que, celebrándose el día 12 del presente mes, en la Basílica de Guadalupe en México, la fiesta anual que corresponde a esta diócesis, que también celebro anualmente aquí, pienso celebrarla, aprovechando tan buena coyuntura, en esa ciudad, con misa pontificial y todo el esplendor posible, tanto más que la ciudad de Tuxtla reconoce como patrona especial a la Sma. Virgen de Guadalupe, cuya fiesta y feria celebran en diciembre, y alguna vez tuve yo el gusto de celebrarla con la solemnidad indicada. Creo que esto, en vez de entorpecer la solemnidad que le corresponde a su matrimonio, que por mi parte deseo que sea con el mayor esplendor posible, como es debido, contribuirá la fiesta indicada a darle más realce, pudiendo reputarse como parte suya. ${ }^{55}$

Con base en las consideraciones anteriores, puede afirmarse que alrede. dor del enlace matrimonial del gobernador se entretejian historias e intereses políticos ajenos al acto en sí mismo. Quienes encabezaban dos estructuras de poder fundamentales dentro de la entidad (la gubernamental y la vertiente católica del plano religioso), vislumbraron la posibilidad de abrir un espacio en el que las contradicciones intraelitistas (forjadas entre luces y sombras regionales, matizadas con tintes étnico-clasistas y mezcladas con cuestiones confesionales) se diluyeran. Vista en abstracto parecía una buena

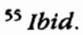


medida; sin embargo, el momento quizá fue mal calculado (el punto álgido de los enfrentamientos se conservaba fresco en una memoria colectiva, a la que no se le había dado tiempo para digerir la guerra del año anterior) y la respuesta popular subestimada.

Independientemente de lo que en el plano cupular pudiera acordarse, el chiapaneco medio no parecía dispuesto a poner punto final a un conflicto que respondía a pesos y contrapesos sobre los que él carecía de control. La lucha por la hegemonía entre los dos sectores principales de la elite había ya transminado sus efectos en los distintos puntos del tejido social y, dependiendo del lugar de residencia, se manifestaban identificaciones y se construían enemistades que tenían poco que ver con la posición que cada uno de los tuxtlecos y coletos involucrados ocuparan dentro de la sociedad.

La idea de que Orozco y Jiménez tendría de rodillas al gobernador ciertamente molestó a quienes consideraban al obispo como su principal adversario. Con la anuencia del presidente municipal (Rodulfo Gamboa) se organizaron grupos en los barrios para protestar por la visita episcopal, e incluso se corrió el rumor de que había entre ellos individuos dispuestos a asesinar al obispo. En realidad, si bien la noticia se difundió ampliamente poco antes de la boda, desde dos meses atrás ya se conocía, según puede deducirse de una carta enviada a Madero, en la que un militar se pone a las órdenes del presidente y le informa que en Tuxtla son fieles a la causa maderista y no desean a orozquistas y zapatistas por traidores. Asimismo, le dice que con la llegada de Orozco al casamiento de Flavio Guillén se esperan conflictos. ${ }^{56}$

Los niveles de espontaneidad y/o manipulación que rodearon al movimiento son difíciles de precisar; desde nuestro punto de vista, ambos elementos estuvieron presentes, aunque testimonios y reseñas de la época tienden a presentar la situación en uno u otro sentido. ${ }^{57}$

Para los partidarios de que el prelado llegara a Tuxtla, se trató de una maniobra encabezada por sectores poco representativos de la sociedad local. En una carta enviada por Jesús Martínez Rojas al periódico La Nación, se afirma que "la buena sociedad tuxtleca ha sabido apreciar en lo justo las grandes virtudes y las altas dotes del digno pastor de la Iglesia chiapaneca", y se resaltan las cualidades de Orozco y Jiménez, contradiciendo las versiones de su supuesta participación en la guerra del año anterior. ${ }^{58}$ Flavio Guillén comparte esta postura:

Tuxtla, en su parte social sensata y decente opinó por qué no habría desorden si el obispo llegaba y así me lo manifestaron más de ochenta caballeros en la casa de doña Hermelinda. Pero un grupito de tontos, que soñaba con mantener la división, me llevó al pueblo a

56 "La porra de un pueblo rechaza al obispo. El prelado sacude el polvo de sus sandalias y va a evangelizar otros pueblos", La Nación, 13 de octubre de 1912, México, D. F.

${ }^{57}$ Carta del mayor J. Cabrera Torres a Francisco I. Madero, Tuxtla Gutiérrez, 15 de agosto de 1912, AG̀N, Fondo Francisco I. Madero, caja 27, exp. 738-2, f. 020940-43.

${ }^{58}$ J. Martínez Rojas, "El Ilmo. señor obispo Dr. don Francisco Orozco y Jiménez", La Nación, 13 de octubre de 1912, México, D. F. 
mi casa para pedirme que no llegara el obispo a Tuxtla. Hablé al grupo desde mi balcón y le interrogué si quería, después de oír mis razones, que viniera el obispo y en masa contestó que sí, dejando en ridículo a los organizadores. ${ }^{59}$

Aunque tal versión de los sucesos apareció también en algunas notas periodísticas, ${ }^{60}$ en otra se resalta la gran indignación de los tuxtlecos que, de manera ordenada y pacífica, solicitaron al gobernador que el obispo no oficiara la boda y "menos que este sujeto viniera a la población". 61 De acuerdo con esta segunda cara de la moneda, Guillén se obstinaba en burlarse de un pueblo exasperado; por lo menos en estos términos se refería al asunto el presidente municipal de Tuxtla cuando envió un telegrama a Madero para que interviniera y evitara así "el derra-

\footnotetext{
${ }^{59}$ Guillén, Hijos, 1914, p. 163 (texto en cursivas, subrayado en el original).

${ }^{60}$ De acuerdo con El Imparcial, la manifestación se disolvió cuando la gente, convocada por el presidente municipal a través de los jefes de sección, se dio cuenta de lo que se trataba; se menciona asimismo la presencia de rurales y gendarmes y el telegrama que envió Rodulfo Gamboa a Madero para justificarse. En La Actualidad se publica, de manera extem. poránea, una carta que más de 500 personas enviaron al gobernador al dia siguiente de los hechos mencionados, asegurándole "que la manifestación de anoche no puede ni debe ser estimada como del pueblo tuxtleco". Véase "Protestas contra el señor obispo. Un mensaje de la capital de Chiapas al presiente", El Imparcial, 19 de octubre de 1912, México, D. F., y "Protesta", La Actualidad, 24 de octubre de 1912, México, D. F.

61 "No quieren que vuelva el señor obispo. A este fin el pueblo llevó una ordenada manifestación por las calles", El Intransigente, 8 de octubre de 1912, México, D. F.
}

mamiento de sangre honrada y leal". ${ }^{62}$ Días más tarde, Gamboa envió una carta al presidente, en la que le hacía notar que el pueblo tuxtleco era liberal y no anticlerical; asimismo, le mencionaba que los problemas sucitados durante 1911 habían sido por culpa de Orozco, y de allí la exaltación que el anuncio de su llegada provocó en la capital estatal. ${ }^{63}$

Si rescatamos la esencia de los datos hasta aquí reseñados, podríamos llegar a la conclusión de que existía un claro descontento popular, capitalizado por adversarios políticos de Guillén y enemigos de Orozco. Apoyando esta hipótesis encontramos una hoja impresa fechada en Tuxtla Gutiérrez el 13 de octubre de 1912; su autor firmó como si fuera "un viajero" que casualmente se había convertido en "testigo presencial" de los hechos, al "que ni de cerca ni de lejos me interesan las cosas que en Chiapas pasan", ${ }^{64}$ pero a lo largo de su exposición se detectan conocimientos sobre la realidad local, que no corresponden con ese perfil.

El conjunto del documento apoyaba al obispo; su encabezado colocaba como destinatario al director del periódico La Prensa y desde el inicio se

62 Ibid.

${ }^{63}$ Carta de Rodulfo Gamboa a Francisco I. Madero, Tuxtla Gutiérrez, 18 de octubre de 1912, AGN, Fondo Francisco I. Madero, caja 13, exp. 302-1, f. 9792-97.

64 "CHIAPAS. El Ilmo. señor obispo de Chiapas y los sucesos de Tuxtla Gutz. LO QUE INFORMA UN TESTIGO PRESENCIAL DE LOS ACONTECIMIENTOS. ¿AQUELLA CAPITAL ES PATAGONLA?", Tuxtla Gutiérrez, 13 de octubre de 1912, hoja impresa, Archivo personal de la familia Guillén Castañón. 


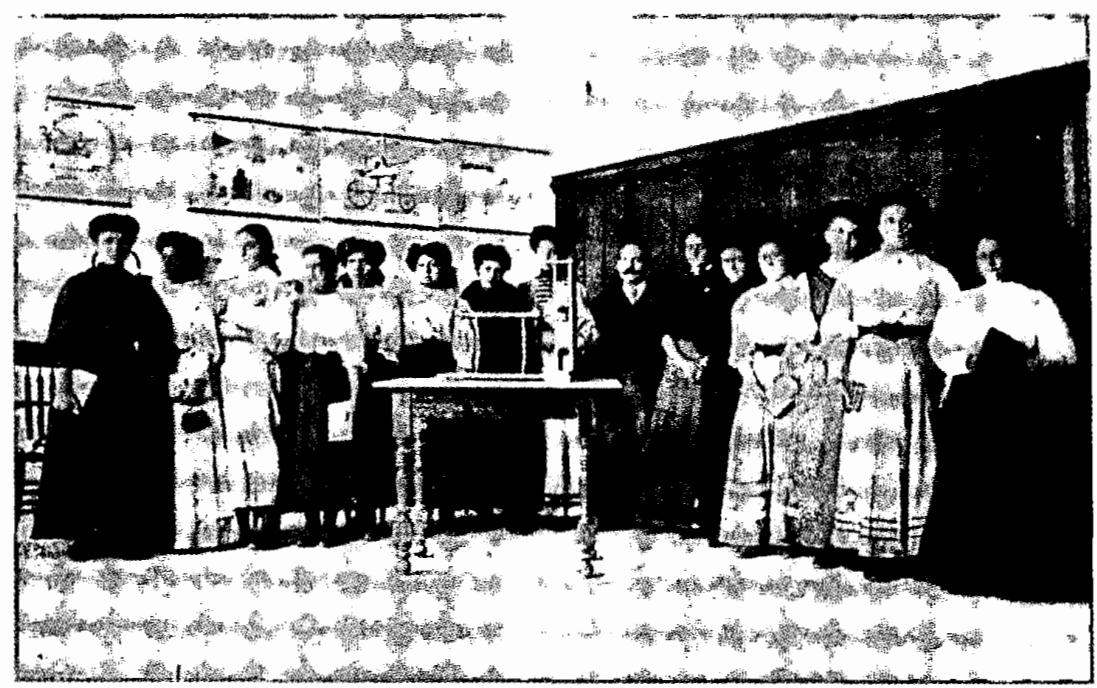

estipulaba que el único propósito de la misiva, originada por un "impulso natural de indignación", era hacer "del conocimiento de todos los mexicanos católicos y no católicos, el tristísimo papel que desempeña entre las poblaciones cultas y civilizadas la capital de este estado" (se refiere a Chiapas). Del relato se desprende que por cuestiones de negocios el supuesto viajero se encontraba en Tuxtla el 7 de octubre cuando:

con la rapidez del rayo se extendió en la ciudad la noticia de la llegada del obispo chiapaneco; haciéndose a este respecto los más sabrosos comentarios, entre los cuales figuran los que escuché en el antiguo hotel de Paco -iqué hubo? -que ha de haber, hombre, que llega el obispo -iqué obispo? ¿el de Oaxaca? No, el de San Cristóbal, ese guerrero... ese intrigante... ese enemigo de Tuxtla. Pues aquí no entra, decía uno; no, no debe entrar, replicaba el otro; unámonos y levantemos al pueblo para impedir que llegue quien tanto daño nos ha hecho. Sí, ha sido un pueblo noble, culto y honrado, y la llegada de ese obispo nos mengua y nos deshonra (molleras de conejos, decía yo para mis adentros, a la vez que tomaba una sabrosa zapoteca). Bueno, iy a qué viene el obispo?, aquí está el "Diario", a ver, a ver, y boquiabiertos todos, como el buzón de correos, comienza la lectura: "El atrevimiento del obispo Orozco y Jiménez no tiene igual". ${ }^{5}$ iBra-

${ }^{65} \mathrm{El}$ autor se refiere al titular con el que un periódico local publicó la noticia. "El atrevi. miento del obispo Orozco y Jiménez no tiene igual", El Diario de Chiapas, s. f., Tuxtla Gutiérrez, Archivo personal de la familia Guillén Castañón. 
vo, bravo! "Sabemos de buena fuente que el gobernador ha invitado al señor obispo para que celebre su matrimonio canónico con la señorita Isabel Castañón." ¿Qué barbaridad! dice uno. Es un bofetón para Tuxtla, dice otro. No, no, hagamos manifestaciones públicas, esta misma noche iremos a la casa del gobernador $y$ le pediremos que no venga el obispo[...]. ${ }^{66}$

De acuerdo con la misma fuente, los manifestantes no fueron recibidos esa noche; al día siguiente se realizó un nuevo mitin, y esta vez Guillén intentó, sin éxito, convencer al grupo de inconformes, quienes, después de escucharlo, lanzaron vítores para honrarlo a él y a la ciudad, pero se negaron a aceptar la presencia de Orozco y Jiménez. El texto insistía en la poca cultura e inteligencia de aquellos que así obraban, y concluía elogiando la valentía del gobernador al cambiar la sede de su matrimonio para que el obispo pudiera oficiar la misa sin contratiempos. Finalmente, se incluía el agregado de un "subscritor" [sic] en el cual se narraba el último intento realizado por Rodulfo Gamboa, el 10 de octubre, para movilizar a la gente, y la respuesta de Guillén enviando a la fuerza pública. ${ }^{67}$

Las memorias de don Flavio omiten la primera de estas tres protestas, y el resto de la hemerografía y testimonios consultados consignan fundamental-

66 "CHIAPAS. El Ilmo. señor obispo de Chiapas y los sucesos de Tuxtla Gutz. LO QUE IN. FORMA UN TESTIGO PRESENCIAL DE LOS ACONTECIMIENTOS. ¿AQUELLA CAPITAL ES PATAGONIA?", Tuxtla Gutiérrez, 13 de octubre de 1912, hoja impresa, Archivo personal de la familia Guillén Castañón.

${ }^{67}$ Ibid. mente la última de ellas. Según el relato del gobernador, sólo hubo dos momentos en los que, mediante la presión popular, se intentó hacerlo cambiar de opinión, y ambas coyunturas fueron controladas sin ningún problema; mientras en una, como veíamos antes, y contrariamente a las afirmaciones del "viajero" a La Prensa, convenció a los inconformes, en la otra le dijo al mayor Cabrera (jefe de rurales):

vaya usted a disolver ese populacho a cintarazos; ¿y si alguno dispara sobre nosotros? Entonces carguen sobre ellos, mandaré más fuerza armada y mañana [eran las 9 de la noche] contaremos los muertos. El pueblo se disolvió con sólo oír mi orden. ${ }^{68}$

Fuesen una o tres manifestaciones, y se mantuviesen $o$ abandonasen sus consignas, el descontento ante la visita del prelado era compartido por varios sectores de la sociedad tuxtleca; queda abierta la posibilidad de que el rechazo hacia a Orozco y Jiménez no representara el sentir de la mayoría y la intimidación armada se hubiese limitado a restarle fuerza a movimientos manipulados desde la cúpula, pero aun así, e independientemente de la capacidad del ejecutivo estatal para manejar el conflicto (por la vía de la conciliación y/o del enfrentamiento), una vez desencadenado éste se esfumaron las ventajas conciliatorias que en un principio favorecían la participación del obispo en su matrimonio.

El escenario que emergía en medio de los preparativos para la boda tam-

${ }^{68}$ Guillén, Hijos, 1914, pp. 163 y 164. 
poco se ajustaba a los planes de Orozco, quien se había trasladado a Chiapa de Corzo desde el 9 de octubre. Se supone que el alto en el camino antes de proseguir su trayecto hacia Tuxtla era "por haber estado en días pasados enfermo de reumatismo auricular, que me alarmó un poco y me puso en cama". ${ }^{69}$ La carta de principios de ese mes, en la que incluía tal justificación para su itinerario y preguntaba al gobernador si éste era viable, queda como constancia de que el obispo pensaba detenerse en Chiapa aun antes de que las manifestaciones en su contra tuviesen lugar. Se tratara en efecto de cuestiones vinculadas con la salud o más bien de previsiones políticas que dificilmente conoceremos, el haber realizado una escala de dos días le dio cierto margen para replantear los pros y los contras de su presencia en la capital de la entidad.

Cuando finalmente tomó la decisión de interrumpir el viaje, más que el temor por su seguridad personal, que en todo caso también se encontraba amenazada, buscaba evitar un nuevo enfrentamiento entre Tuxtla y San Cristóbal. A un año de la guerra entre las dos ciudades, el desaire realizado al obispo podía encender de nuevo las brasas que en ambos sitios se mantenían vivas. Aunque las divisiones entre unos y otros respondían a procesos de mayor alcance, en ese momento los antagonismos se sintetizaban alrede-

${ }^{69}$ Carta de Francisco Orozco y Jiménez, obispo de Chiapas, a Flavio Guillén, gobernador del estado, San Cristóbal, L. C., octubre 3 de 1912. Archivo personal de la familia Guillén Castañón. dor de la participación del obispo en el matrimonio religioso del gobernador.

El ilustrísimo señor obispo espera en Chiapa la decisión del gobernador. El pueblo chiapaneco sancristobalense se halla excitado con motivo de la celebración del aniversario de la defensa heroica del 8 de octubre del año pasado, y desea un pretexto para una fricción con los tuxtlecos. En todo el estado ha escandalizado el indigno proceder de los políticos tuxtlecos y se dice faltan garantías en la capital de Chiapas. El presidente del centro católico, licenciado Juan F. Zepeda, deseoso de evitar fricciones sangrientas entre los católicos de Chiapas y los porristas tuxtlecos, se dirigirá al presidente del partido para que pida garantías al presidente de la república para el ilustrísimo diocesano. Se espera se impongan enérgicas medidas. $^{70}$

Vista en retrospectiva, la conyuntura que se delineó implicaba altos niveles de agitación (provenientes del largo y del corto plazo), pero nunca dispuso del tiempo para transformarse en una nueva disputa armada; las moviliza. ciones en Tuxtla tuvieron lugar entre el 7 y el 10 de octubre, y Orozco mandó un telegrama al gobernador con su resolución de no asistir a la boda el 11 de octubre, ${ }^{71}$ situación que contribuyó a restarle intensidad al conflicto y redujo espacios para la reacción alteña.

70 "Se pedirán garantías al Sr. Pte. IExiste el deseo de que el señor obispo Orozco y Jiménez no sea molestado", La Nación, 13 de octubre de 1912, México D. F.

${ }^{71}$ El prelado aducia que quería evitar desgracias y que "ya castigaría a los feligreses cómplices", Guillén, Hijos, 1914, p. 164. 
Es de resaltar la celeridad con la que el prelado se ajustó a los acontecimientos; todavía el 9 de octubre había en. viado una carta abierta a Guillén y en ella desmentía las acusaciones en su contra, además de culpar por pretender envolverlo en un movimiento del que era ajeno, a quienes "no veían con buenos ojos les impartiera a los indios instrucción, cariño y benevolencia". Concluía su alegato otorgándole plena libertad a don Flavio para que hiciera el uso que creyese conveniente de la carta y reiterándole:

Respecto de mi viaje a Tuxtla en las actuales circunstancias, por mi parte, no tengo más que confirmarle mi ofrecimiento ya hecho. iOjalá que mi presencia sea mensajera de paz, de bienandanza y de verdadera felicidad para esa ciudad, que algunos no quieren comprender amo positivamente! ${ }^{72}$

El cambio en la postura del obispo estuvo muy probablemente influido por consideraciones de índole política. El gobernador ya había demostrado que no se dejaría intimidar y que, de ser necesario, utilizaría incluso la fuerza para mantener la invitación girada a Orozco; sin embargo, los costos de una acción de este tipo podían ser muy altos, y lejos de contribuir a mejorar la postura del jerarca eclesiástico, ahondarían los ya de por sí profundos recelos hacia su figura.

\footnotetext{
${ }^{72}$ Carta impresa de Francisco Orozco y Jiménez, obispo de Chiapas, al señor don Flavio Guillén, gobernador del estado, Chiapa de Corzo, 9 de octubre de 1912. Archivo personal de la familia Guillén Castañón.
}

El telegrama del 11 de octubre representaba una decisión inteligente y que evitaba males futuros, pero al mismo tiempo significaba el triunfo de quienes se habian enfrentado al ejecutivo estatal. A esas alturas, el entramado que habían formado los planos público y privado era ya evidente, y todo parecía indicar la derrota de Guillén en ambos. Por un lado, su autoridad quedaba disminuida y, por el otro, se le obligaba a suspender su boda, o bien a elegir a alguien más para oficiarla. Se trataba de una disyuntiva complicada, sobre todo si consideramos que don Flavio entendía las razones del obispo y estaba consciente de los riesgos que implicaba el seguir adelante con sus planes matrimoniales. ${ }^{73}$

Argumentando que "no se trataba de nada oficial, sino de un acto particular de mi vida privada, por la cual haría yo mal en derramar sangre", el gobernador finalmente decidió trasladarse a Chiapa de Corzo, para que en esa población lo casara Orozco y Jiménez. ${ }^{74}$ De acuerdo con lo previsto, el 12 de octubre se celebró la ceremonia civil en Tuxtla, y para festejarlo se rea-

\footnotetext{
${ }^{73}$ En estos términos se refiere al episodio: "Pero el obispo, muy inteligente, comprendió que con no ir a Tuxtla la castigaría más, como en efecto fue, pues nunca se quitará ese baldón de intransigencia. La gente sensata y culta de Tuxtla lo sintió mucho y reprobó las intrigas de Rodulfo Gamboa", Guillén, Hijos, 1914, p. 164.

74 "El asunto del Ob. de Chiapas. El gobernador Guillén irá a Chiapa a contraer matrimo nio", El Imparcial, 13 de octubre de 1912, México, D. F.; "No llega a Tuxtla Gutiérrez el Ilmo. Sr. Ob. Francisco Jiménez", La Nación, 15 de octubre de 1912, México, D. F.; "Ya se arregló el conflicto en Chiapas", Diario Español, 13 de octubre de 1912. México. D. F.
} 
lizaron al mediodía un banquete informal en la casa de don Flavio y por la noche un baile en el Teatro del Estado; asimismo, en otros puntos de la entidad se organizaron fiestas que conmemoraban la ocasión. ${ }^{75}$

A las 6 de la mañana del día siguiente (13 de octubre), la comitiva que asistiría al acto religioso se encaminó hacia Chiapa. Contra viento y marea sería el obispo quien impartiese la bendición nupcial, pero lo haría en un escenario menos agitado. ${ }^{76}$ Parecía una decisión salomónica, en la que se respetaba el ámbito público del conflicto (el espacio simbólico construido alrededor de la capital se mantendría ajeno al acontecimiento) y, al mismo tiempo, se sostenía una elección de carácter privado (quién oficiaría el matrimonio); sin embargo, los dos niveles guardaban estrecha relación y, por tanto, muchos tuxtlecos se sintieron burlados, y otros tantos alteños (Orozco a la cabeza) acusaron recibo del desaire.

Lejos de ponerse fin a la disputa, cuando los novios cubrieron los poco más de quince kilómetros (tres leguas señalan las fuentes de la época) que separan a Tuxtla de Chiapa, los hilos

75 “El 12 del corriente", El Progreso, 13 de octubre de 1912, Tapachula; "Matrimonio Guillén-Castañón", Diario de Cbiapas, 13 de octubre de 1912, Tuxtla Gutiérrez; hoja impresa de invitación a serenata, 12 de octubre de 1912, Comitán, Archivo personal de la familia Guillén-Castañón.

${ }^{76}$ Existe la versión de que cuando un grupo de tuxtlecos propuso al gobernador que si insistía en llevar adelante el rito religioso invitase a "cualquier otro cura", éste respondió que "de no ser Orozco y Jiménez, ni el santo padre lo casaría", entrevista a Carlos Castañón, Tuxtla Gutiérrez, marzo de 1990. que habían entretejido su trayectoria personal y familiar con la historia de la entidad condujeron a un nuevo episodio. Después de realizarse la ceremonia, se ofreció un banquete en el que el obispo hizo uso de la palabra para decir que "su felicidad consistía en la felicidad de los pueblos todos de Chiapas, sin ser exclusivista para preferir determinado lugar del estado", además de mencionar lo honrado que se sentía "con haber dado la bendición nupcial a la distinguida pareja". ${ }^{77}$

Las palabras del prelado se sumaron a las crónicas del acontecimiento, en las que se resaltaban las muestras de simpatía hacia los contrayentes y hacia Orozco, de allí que por momentos pareciese que las aguas habían vuelto a tomar su curso. En realidad otro escenario se configuraba tras bambalinas; ese mismo día (13 de octubre), "por la gracia de Dios y de la Santa Sede", el obispo castigó a sus opositores con un entredicho dirigido en los siguientes términos a la parroquia de Tuxtla Gutiérrez:

La Iglesia siempre sabia en todas las disposiciones cuando llega el caso de que algunos de sus hijos delinquen, ha puesto a disposición de los superiores eclesiásticos la facultad de hacer uso de los medios conducentes a repetir su contumacia y rebeldía cuando después de corregidos y amonestados no vuelven sobre sus pasos. Hoy me veo, a pesar mío, como legítimo prelado de la Iglesia de Chiapas en el duro caso de llamar al orden a los habitantes de Tux-

7 Véase "El matrimonio del Gob. Guillén", El Imparcial, 14 de octubre de 1912, México, D. F. 
tla Gutiérrez y de aplicarles las penas extremas de entredicho, pues hace más de un año que de la manera más hostil y gratuita se han ensañado contra nosotros. despreciando apremiantes amonestaciones y terminantes imitaciones y abusando aun de nuestra paternal deferencia y solicitud. Sobre todo esto, agréguese que hoy día las cosas han llegado a los inauditos extremos de rechazarme en la forma más escanda. losa y ruidosa por medio de públicas manifestaciones; se nos ha insultado y calumniado de palabra y por escrito. ${ }^{78}$

En el documento se resaltaban también los supuestos planes para atentar contra la vida de Orozco si llegaba a la capital de la entidad, y se denunciaba la actitud pasiva de "un vecindario que de esa manera se hacía solidariamente responsable". Asimismo se mencionaban la amistad y respeto que existían entre el gobernador y el prelado, destacándose la oposición abierta del ejecutivo estatal hacia el movimiento y la necesidad de su depositario de trasladarse a Chiapa de Corzo para recibir "una bendición nupcial que hoy mismo le hemos dado con gran satisfacción". Finalmente, y luego de afirmar en latín y español "Yo nutrí y ensalcé a mis hijos y ellos me han despreciado", se declaraba a la ciudad de Tuxtla en estado de ENTREDICHO por el lapso de un año, "esperando que antes de ese término Dios Ntro. Señor, Padre de

\footnotetext{
7 "Entredicho", Boletín Eclesiástico del Obispado de Cbiapas, tomo II, núm. 6, San Cristóbal L. C., noviembre 20 de 1912, pp. 101102. Archivo personal de la familia Guillén Castañón.
}

bondad y misericordia, mueva los corazones al debido arrepentimiento". ${ }^{79}$

Para los afectados se trató de una demostración de ira en tono burlón calificada de santa, ${ }^{80}$ mientras que para los partidarios de Orozco se hizo un buen uso de la jurisprudencia eclesiástica. Los primeros veían en la medida la mano de un personaje tortuoso que buscaba vengar afrentas personales, y los segundos resaltaban la necesidad de responder en forma institucional ante agravios que afectaban a la Iglesia misma. ${ }^{81}$ Una vez más el análisis obliga a matizar posturas que en principio se tiñen de blanco o de negro dependiendo de quién las asuma; es muy probable que el obispo haya valorado los costos corporativos de ignorar una provocación como la que se había lanzado a la máxima autoridad eclesiástica del estado y, también, resulta plausible que en su interior se desataran sentimientos de enojo y frustración por el trato del que había sido objeto.

Sea cuales fueren los motivos del obispo, el capítulo con el que se cerraba la trama surgida alrededor del en-

${ }^{79}$ Ibid., p. 102.

${ }^{80)}$ Véase Espinoza, Iras, 1912.

${ }^{81} \mathrm{Al}$ parecer los sacerdotes que estaban con Orozco (los que se reunieron en Chiapa de Corzo y los doce clérigos que lo habían acompañado desde San Cristóbal para oficiar la boda) tuvieron que insistir para que el obispo finalmente decretara la interdicción. Incluso le mencionaron otros momentos de la historia en los que se había sentado jurisprudencia al respecto e hicieron énfasis en el caso de Pío X, quien a pesar de la bondad que lo caracterizaba, había actuado contra feligreses que bajo el influjo del marxismo lo repudiaron cuando era arzobispo patriarca de Venecia. Véase Camberos, Francisco, 1966, p. 213. 


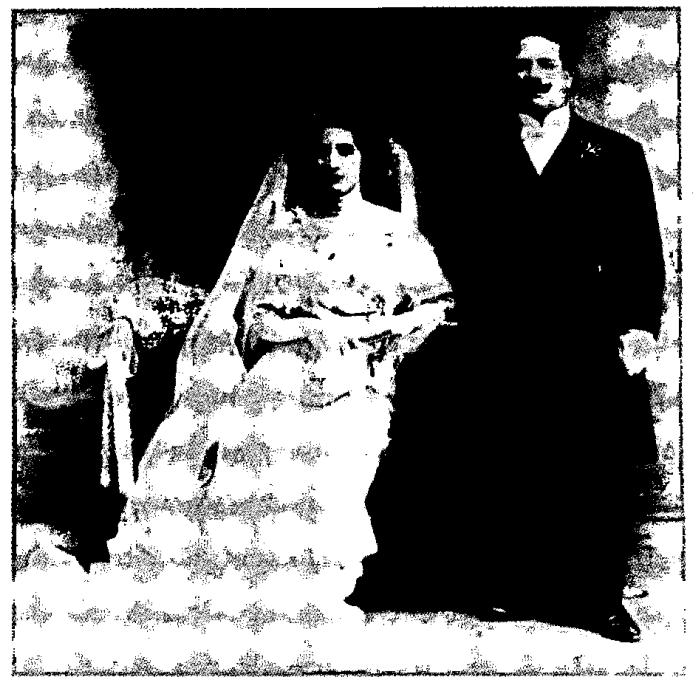

lace Guillén-Castañón constituyó su última actuación pública en Chiapas. Era obvio que, lejos de redituarle los beneficios políticos esperados, la boda del gobernador había complicado su situación en la entidad y no tenía mayor sentido permanecer en una diócesis que había escapado de su control. Al día siguiente (14 de octubre) Francisco Orozco y Jiménez abandonó Chiapas y, sin pasar por Tuxtla, se dirigió a la ciudad de México, donde permaneció unos días antes de partir con rum. bo a Zamora.

Desde mi punto de vista, su decisión de dejar atrás a la feligresía que se le había asignado estuvo íntimamente vinculada con un fenómeno al que hoy en día denominariamos ingobernabilidad. Las dificultades para llevar al redil a quienes se habían salido del rebaño, le dejaban básicamente dos caminos: permanecer en la entidad desafiando a sus opositores y reconstruyendo su poder, o bien aceptar las pérdidas y evitar acrecentarlas buscando nuevos horizontes. Para entonces el obispo ya había informado al Vaticano de lo sucedido, y sólo le restaba esperar noticias de la Santa Sede para saber cuál sería su futuro.

Mientras tanto, los tuxtlecos habían dividido reacciones; hubo quienes sugirieron la posibilidad de "tomar posesión previo inventario", de los sitios que pertenecían a la Iglesia, "por ser todo eso propiedad de la nación", 82 y hubo otros que se acercaron a Guillén

82 "Entredicho", Diario de Chiapas, s. f., Tuxtla, Gutiérrez, Archivo personal de la familia Guillén Castañón. 
rogándole que interpusiera su influencia ante la arquidiócesis "para que se levantara tan tremendo castigo". ${ }^{83} \mathrm{Se}$ gún Luis Espinoza, estos últimos constituían una minoría:

En cuanto al efecto producido por el ENTREDICHO en la ciudad de Tuxtla de Gutiérrez, me enorgullece manifestar que ha sido el de la más absoluta indiferencia. En estos tiempos de luz y de libertad, los ENTREDICHOS sólo sirven para hacer reír y para poner en la picota del ridículo a los obispos que, como el de Chiapas, hacen la ilusión de que viven en los tiempos tenebrosos de fray Juan de Zumárraga. ${ }^{84}$

En realidad, fuera de la ya mencionada solicitud que hiciera un grupo al gobernador para que intercediese en favor de ellos ante las autoridades eclesiásticas y se levantara el castigo, no encontramos mayores pruebas de pesar o arrepentimiento entre aquellos que se habían quedado sin un espacio formal para practicar el catolicismo. Dudamos sin embargo que el conjunto de la población compartiera la postura radical de Luis Espinoza, quien en su alegato anticlerical incluso retaba a la Iglesia a mantener el entredicho durante el lapso marcado (un año), y resaltaba los beneficios de vivir al margen de la fe. ${ }^{85}$

Suponemos que, además de dirigirse a Guillén, los afectados buscaron canales eclesiásticos para restablecer el culto en Tuxtla. Sin embargo, a partir de las fuentes con las que contamos, resulta difícil determinar si lo hicieron o no y, en caso afirmativo, establecer el papel que jugaron tales presiones a la hora de levantar el entredicho. Según Vicente Camberos, el obispo recibió múltiples cartas provenientes de la diócesis, y en ellas, además de solicitarle que regresase, "todas las clases sociales reiteradamente imploraban clemencia para la ciudad anatematizada" ${ }^{86}$

El entredicho finalmente se levantó poco más de un mes después de haberse aplicado (21 de noviembre), pero ninguna de las dos versiones construidas alrededor de los sucesos explica las razones de tal suspensión. El propio Camberos admite ignorar "qué circunstancias originaron la determinación absolutoria", máxime que hasta varios días después llegaron las "esperadas orientaciones de la superioridad", pero se inclina a interpretarla como un acto de cariño y perdón. ${ }^{87}$

Aquí habría que recordar que en ese momento Orozco vivía una situación de impasse, lo que dificulta aceptar tal hipótesis; a nuestro modo de ver, al recurrir a un castigo que desde la colonia no se aplicaba en México, el obispo echó a andar una maquinaria institucional cuyo funcionamiento ya no dependía sólo de él. A partir de esta idea, nos parece probable que haya contado con la venia de las autoridades canónicas para suspender el entredicho. Es cierto que la decisión del Vaticano sobre su caso se le notificó hasta diciembre, pero antes de recibir la comunicación oficial, bien pudo haber

\footnotetext{
${ }^{86}$ Camberos, Francisco, 1966, p. 214.

${ }^{87}$ Ibid.
} 
establecido contactos informales con sus superiores.

Aunque las pugnas políticas y sociales derivadas del matrimonio GuillénCastañón concluyeron con el restablecimiento del culto católico en Tuxtla Gutiérrez, otros conflictos surgieron a partir de entonces en el escenario chiapaneco. Las fracturas regionales se mantuvieron hasta que el proceso revolucionario iniciado en 1910 obligó a cerrar filas a las distintas fracciones de la elite local, y posteriormente consolidó la hegemonía de quienes representaban a los valles centrales. ${ }^{88} \mathrm{La}$ distribución regional del poder ha sufrido algunos cambios desde entonces, pero todavía persisten las secuelas de una rivalidad que en 1911 condujo a la guerra y en 1912 propició el enfrentamiento abierto con la autoridad eclesiástica asignada a la entidad. ${ }^{89}$

Para concluir, y como epílogo al episodio de la microhistoria de Chiapas que motivó estos apuntes, recordaríamos que Flavio Guillén abandonó la gubernatura meses más tarde (febrero de 1913), en medio de una pugna con el Congreso local y enfrentando serios problemas de legitimidad. ${ }^{90}$ Francisco Orozco y Jiménez fue nombrado arzobispo de Guadalajara (di-

\footnotetext{
${ }^{88}$ Los detalles de las implicaciones de la revolución para la elite chiapaneca pueden consultarse en Pérez y Guillén, Chiapas, 1994, pp. 225-244

${ }^{89}$ Cualquiera que visite Chiapas podrá constatar las identidades antagónicas que se han construido alrededor de la antigua Ciudad Real y de Tuxtla Gutiérrez.

${ }^{90}$ Los detalles de la salida de Guillén pueden consultarse en Guillén, Maderismo, 1994, pp. $73-75$.
}

ciembre de 1912), y si bien ello significó el reconocimiento hacia la labor previamente realizada, los saldos de su estancia en Chiapas fueron más bien negativos. La respuesta que el propio Orozco dio a otro sacerdote (Narciso Aviña y Ruiz) cuando éste lo felicitó por su nueva investidura, ilustra claramente el sentir del prelado: "No me felicites... ¿Luego Chiapas? Debías más bien darme el pésame."

La vida de ambos personajes no volvió a cruzarse; don Flavio salió exiliado para Guatemala a raíz de la Decena Trágica y en aquel país vivió el resto de sus días, mientras que Orozco radicó intermitentemente en México y en el extranjero, evadiendo la persecución a la que se hizo objeto por enfrentar abiertamente la política anticlerical de los primeros gobiernos revolucionarios. A pesar de las diferencias que pudieron haber tenido las trayectorias de cada uno de ellos (antes y después de la boda), en su momento los acontecimientos derivados de dicho evento social marcaron el destino de un obispo y un gobernador; la renuncia de Guillén tuvo como detonante su postura a propósito de las jefaturas políticas, ${ }^{92}$

${ }^{91}$ Camberos, Francisco, 1966, p. 217.

92 "En Chiapas se han suprimido las jefaturas. Después de San Luis Potosí, Chiapas es el segundo estado que cumple con el plan", Nueva Era, 23 de octubre de 1912, México, D. F.; "El pueblo de Tuxtla Gutiérrez en solemne manifestación apoyó al ejecutivo", Verdad y Justicia (Alcance al número 16), 18 de diciembre de 1912, Tuxtla Gutiérrez; "La legislatura del E. de Chiapas se muestra intransigente", Nueva Era, 12 de enero de 1913, México, D. F.; Carta de Flavio Guillén a Francisco I. Madero, Tuxtla Gutiérrez, 25 de diciembre de 1912, AGN, fondo Francisco I. Madero, caja 13, exp. 302-1, f. 9813 . 
pero las circunstancias en las que contrajo matrimonio le restaron apoyos necesarios para sobrellevar tiempos cuya convulsión iba más allá de la tormenta relacionada con su matrimonio, ${ }^{93} \mathrm{y}$, en el mismo sentido, aunque la salida de Orozco de la diócesis se debió al conjunto de sus actos en la entidad, la gota que derramó el vaso de agua fue la coyuntura generada en octubre de $1912 .{ }^{94}$

Pondríamos pues punto final a nuestro recorrido, resaltando las ventajas de hacer dialogar razones de Estado y decisiones políticas con trayectorias y coyunturas personales. En su conti-

16; Carta del coronel Lindoro Castellanos a Francisco I. Madero, AGN, fondo Francisco I. Madero, caja 44, exp. 1214-2, f. 33797-800.

${ }^{93}$ Resulta ilustrativa la carta dirigida a Madero que en diciembre de 1912 firmaron más de 200 tuxtlecos para solicitar el regreso de Gordillo León. El argumento central era la falta de armonía entre un gobernante que no procuraba la salud pública y gobernados que se desesperaban, pero el párrafo dedicado a la visita de Orozco dejaba en claro cuál era la principal fuente de malestar: "Con motivo de los sucesos acaecidos, en que se nos quiso obligar a recibir triunfalmente y por la fuerza de las bayonetas, para rendirle honores al mayor enemigo de Tuxtla Gutiérrez, el obispo de Chiapas, entonces, señor don Francisco Orozco y Jiménez, incidente del cual tiene usted noticia, ha agriado los ánimos y dia a día se viene exacerbando, al grado que no sabemos hasta dónde pueden llegarse, entre un gobernante que nos desprecia y un pueblo que tampoco lo quiere". Carta a Francisco I Madero, AGN, fondo Francisco I. Madero, caja 61, exp. 834.

${ }^{94}$ Para conocer la versión de Orozco sobre su estancia en Chiapas, puede consultarse un texto que el obispo publicó seis años después de haber abandonado la entidad, reivindicando los resultados materiales y espirituales de su trabajo, Orozco y Jiménez, Acerquémonos, 1918 , pp. $11-13$ y $37-53$ nuo fluir, la historia incorpora esas y otras dimensiones, por lo que también se puede escudriñar en ella a partir de hechos considerados menores, que, sin embargo, dan cuenta de trayectorias más amplias. Con tal idea en mente, el eje central de la exposición giró alrededor de tiempos cortos, pero, para analizar éstos, se recurrió a elementos derivados del largo y mediano plazos. La boda de un gobernador, aderezada con las características particulares de la trayectoria chiapaneca (que son las que le pusieron sal y pimienta), se convirtió en un atractivo objeto para investigar. En este sentido, quizá el saldo más importante que obtuvimos de nuestro trabajo fue la certidumbre de que los microsucesos casi siempre tienen algo que decir sobre procesos sociales de mayor envergadura, $y$, por tanto, su rescate contribuye a enriquecer el debate histórico.

\section{HEMEROGRAFIA}

-Boletín Eclesiástico del Obispado de Chiapas, San Cristóbal de las Casas, Chiapas.

-Diario de Chiapas, Tuxtla Gutiérrez, Chiapas.

-Diario Español, México, D. F. -El Democráta Mexicano.

-El Heraldo de Chiapas, Tuxtla Gutiérrez, Chiapas.

-El Imparcial, México, D. F.

-El Intransigente, México, D. F.

-El Progreso, Tapachula, Chiapas.

-La Actualidad, México, D. F.

-La Nación, México, D. F.

- La Patria.

-Nueva Era, México, D. F.

-Verdad y Justicia, Tuxtla Gutiérrez, Chiapas. 


\section{BIBLIOGRAFÍA}

-Benjamin, Thomas, A rich land, a poor people. Politics and society in modern Chiapas, University of New Mexico Press, Albuquerque, 1989.

- "Revolución interrumpida -Chiapas y el interinato presidencial1911", Historia Mexicana 117, vol. xxx, núm. 1, julio-sept. de 1980.

-Camberos Vizcaíno, Vicente, Francisco el Grande. Monseñor Francisco Orozco y Jiménez. Biografia, Editorial Jus, México, 1966.

-Casahonda, José, 50 años de revolución en Cbiapas, ClaCH, México, 1974.

-Castañón Gamboa, Fernando, "Pano. rama histórico de las comunicaciones en Chiapas", Ateneo, núm. 1, enero-marzo de 1951, Tuxtla Gutiérrez.

-Discurso del licenciado Emilio Ra. basa, gobernador del estado de Chiapas, ante la XXVII Legislatura del mismo, al abrir ésta su primer periodo de sesiones ordinarias, Imprenta del Gobierno dirigida por Félix Santaella, Tuxtla Gutiérrez, 1893.

-Documentos relativos al Congreso Agrícola de Chiapas, Imprenta del Grobierno del Estado, dirigida por Félix Santaella, Chiapas, 1896.

Espinoza, Luis, Independencia de la Provincia de las Chiapas y su unión a México, Imprenta Victoria, México, 1918.

- Iras santas: el entredicbo del obispo de Chiapas, Talleres de S. Larios, México, 1912.

Rastros de sangre. Historia de la revolución en Chiapas, Imprenta de Manuel León Sánchez, México, 1912.

-Favre, Henry, Cambio y continuidad entre los mayas de México, contribución al estudio de la situación colonial en América Latina, Instituto Nacional Indigenista, México, 1984.

- García de León, Antonio, Resistencia y utopia. Memorial de agravios y profecías acaecidos en la provincia de Cbiapas durante los últimos quinientos años de su bistoria, vols. I y II, Era, México, 1985.

-Glass, Elliot S., México en la obra de Emilio Rabasa, Diana, México, 1975.

-Guerra, François Xavier, México del Antiguo Régimen a la Revolución, 2 vols., Fondo de Cultura Económica, México, 1988.

-Guillén, Diana, El maderismo en Cbiapas. Matices regionales del acontecer revolucionario, INHERM, México, 1994 (Col. Premio Salvador Azuela).

-Guillén, Flavio, Para mis bijos: recuerdos autobiográficos redactados y coleccionados en Guatemala, 1914, manuscrito, p. 83. Archivo personal de la familia Guillén Castañón.

-Mallén, B., "La regeneración de la raza indígena", Boletín de la Cámara Agrícola Nacional de Chiapas, vol. I, núm. 8, abril 30 de 1911, Tuxtla Gutiérrez.

-Martínez Rojas, Jesús, Los últimos acontecimientos politicos de Chiapas. Estudio del amparo contra actos de su legislatura que privó al Sr. Lic. José Antonio Rivera $G$. de la mayoria absoluta de votos que obtuvo en las elecciones populares del estado y colocó al derrotado en ellas en el gobierno, Imprenta de A. Carranza e hijos, México, 1912.

-Moscoso Pastrana, Prudencio, Jacinto Pérez "Pajarito", el último líder chamula, Editorial del Gobierno del Estado de Chiapas, México, 1972.

-Orozco y Jiménez, Francisco, Acerquémonos a Dios. Memorándum del arzobispo de Guadalajara, s. 1., s. e., 1918.

-Padilla, Antonio, "La reforma y los bienes de la Iglesia en Chiapas: su desamortización y nacionalización, 1857-1867", Secuencia, Revista Americana de Ciencias Sociales, Instituto Mora, núm. 12, septiembre-diciembre de 1988, México.

-Paz, Eduardo, La cuestión económica y política local en Chiapas, s. e., México, 1912. 
-Pedrero Nieto, Gloria, Las baciendas y los ranchos sancristobalenses del siglo XIX, estudio bistórico, Centro de Investigaciones del Sureste, San Cristóbal de las Casas, 1982.

-Pérez Salas, Ma. Esther y Diana Guillén, Chiapas, una historia compartida, Instituto Mora, México, 1994.

-Reglamento de policía y buen gobierno expedido por el ejecutivo del gobierno de Chiapas el 1 de junio de 1880, Imprenta del gobierno a cargo de Joaquín Armendáriz.

-Rosenzweig, Fernando, "El desarrollo económico de México de 1877 a 1911",
Secuencia, Revista Americana de Ciencias Sociales, Instituto Mora, núm. 12, septiembre-diciembre de 1988, México.

Smithsonian Contribution to Antropo$\operatorname{logy}$, núm. 31.

-Traslación de los poderes públicos del estado de la capital San Cristóbal de las Casas a la ciudad de Tuxtla Gutiérrez, Imprenta de los Chiapanecos Libres en la Frontera a cargo de Celso Costa, Chiapas, 1892.

-Wassertrom Robert, Class and society in central Chiapas, University of California Press, Berkeley, 1983. 